\title{
The Initialization of the MIROC Climate Models with Hydrographic Data Assimilation for Decadal Prediction
}

\author{
Hiroaki TATEBE \\ Japan Agency for Marine-Earth Science and Technology, Yokohama, Japan \\ Masayoshi ISHII \\ Japan Agency for Marine-Earth Science and Technology, Yokohama, Japan \\ Meteorological Research Institute, Japan Meteorological Agency, Tsukuba, Japan
}

\section{Takashi MOCHIZUKI}

Japan Agency for Marine-Earth Science and Technology, Yokohama, Japan Yoshimitsu CHIKAMOTO

Atmosphere and Ocean Research Institute, The University of Tokyo, Kashiwa, Japan

Takashi T. SAKAMOTO, Yoshiki KOMURO

Japan Agency for Marine-Earth Science and Technology, Yokohama, Japan

\section{Masato MORI}

Atmosphere and Ocean Research Institute, The University of Tokyo, Kashiwa, Japan

\section{Sayaka YASUNAKA}

National Institute for Environmental Studies, Tsukuba, Japan

\section{Masahiro WATANABE}

Atmosphere and Ocean Research Institute, The University of Tokyo, Kashiwa, Japan

\section{Koji OGOCHI, Tatsuo SUZUKI, Teruyuki NISHIMURA}

Japan Agency for Marine-Earth Science and Technology, Yokohama, Japan

and

Corresponding author: Hiroaki Tatebe, Research Institute for Global Change, Japan Agency for MarineEarth Science and Technology, 3173-25 Showa-machi, Kanazawa-ku, Yokohama, Kanagawa 236-0001, Japan.

E-mail: tatebe@jamstec.go.jp

(C) 2012, Meteorological Society of Japan 


\title{
Masahide KIMOTO
}

\author{
Atmosphere and Ocean Research Institute, The University of Tokyo, Kashiwa, Japan
}

(Manuscript received 28 February 2011, in final form 27 October 2011)

\begin{abstract}
This paper documents the procedure of ocean data assimilation that initializes the climate models MIROC3m, MIROC4h, and MIROC5 for decadal climate predictions following the CMIP5 protocol, and summarizes the performance of the climate models using this data assimilation. Only anomalies of observed ocean hydrographic data are assimilated using the incremental analysis update method in order to prevent model climate drifts during predictions. In the case of MIROC4h, which has an eddy-permitting ocean model, a spatial smoother is used in calculating analysis increments so that oceanic mesoscale eddies cannot be damped by observational constraints and that they are generated and decay physically in response to the assimilated background state. Globally, the decadal-scale variations of ocean temperatures in the assimilation runs are highly correlated with the observations. Variations of surface air temperature over oceans are also consistent with the observations, but this is not the case in some regions over continents. Atmospheric responses to the SST variations corresponding to the Pacific Decadal Oscillations and the Atlantic Multi-decadal Oscillation are better represented in MIROC4h and MIROC5 than in MIROC3m. The high resolution of MIROC4h and new cloud parameterizations in MIROC5 may contribute to this improvement. Root-mean-squared amplitudes of sea surface height variations associated with oceanic eddies (hereafter, eddy activity) are not suppressed undesirably in the MIROC4h assimilation run and these are comparable with those in the uninitialized runs. In the Kuroshio-Oyashio confluence zone, eddy activity is modulated on a decadal timescale. This modulation is reasonably represented in the assimilation run compared with the observations. In the hindcast experiments, significant decadal prediction skills are found for the North Atlantic, the subtropical North Pacific, and the Indian Ocean. The decadal climate predictions are expected to contribute to the IPCC AR5 and political decision-making for the coming decades.
\end{abstract}

\section{Introduction}

As a part of the Coupled Model Intercomparison Project Phase 5 (CMIP5), a number of decadal hindcast and forecast experiments are in progress using state-of-the-art climate models at research institutes and centers world-wide. The decadal hindcasts and forecasts will contribute towards the Fifth assessment report (AR5) of the Intergovernmental Panel on Climate Change (IPCC).

Detecting the global warming signals due to changes in radiative forcing arising from anthropogenic emissions of greenhouse gases (GHGs) and aerosols was a major focus of the previous assessment report (AR4). Global climate models participating in the IPCC AR4 were used for projections of climate change on a centennial time scale, taking into account observed historical GHG concentrations and the emission scenarios proposed by the IPCC working group. In these studies, the climate models were not initialized, and thus, internal climate variations on interannual-to-decadal time- scales in climate models are not synchronous with the observations.

The purposes of the IPCC AR5 are to address scientific questions that arose as a part of the AR4, to predict the near-term climate up to the year 2030, and to help political decision-making required to enable societies to adapt to climate change in the coming decades. Therefore, in addition to trends of global warming, unforced internal variabilities on a decadal timescale are of great concern.

For the decadal climate predictions, the states of the atmosphere and ocean in climate models need to be initialized by assimilating observations in order to take into account internal climate variations, as done in synoptic-to-seasonal forecasts. In particular, initializing an ocean state is considered to be essential in decadal predictions because signals of decadal climate changes are isolated into the ocean subsurface through air-sea interactions and they are then preserved for over a decade through slowly-varying ocean dynamics. So far, 
the significant roles of the ocean in decadal climate predictability have been investigated by several preliminary studies based on idealized climate model experiments (e.g., Griffies and Byran 1998; Pohlmann et al. 2004; Collins et al. 2006).

Recently, several studies have suggested that skillful predictions of decadal scale climate change based on realistic climate models initialized with ocean data assimilation might be possible (e.g., Smith et al. 2007; Keenlyside et al. 2008; Pohlmann et al. 2009; Sugiura et al. 2009; Mochizuki et al. 2010). Mochizuki et al. (2010) reported that there is potential predictability of almost a decade in the upper ocean temperatures around the Kuroshio and Oyashio Extensions associated with the Pacific Decadal Oscillations (PDO; e.g., Mantua et al. 1997; Mantua and Hare 2002). They also suggested that the negative PDO phase predicted in the decade following 2006 will cancel out the global warming trend in surface air temperature. In the North Atlantic, Keenlyside et al. (2008) showed decadal-scale predictability in changes of the Atlantic Meridional Overturning Circulation (AMOC) and the Atlantic Multi-decadal Oscillations (AMO; e.g., Schlesinger and Ramankutty 1994; Kerr et al. 2000). They suggested that a slowing down of global warming will occur in the decade following 2005. Meanwhile, any given climate model has an individual bias in its model climatology, reproducibility of intrinsic variations, and climate sensitivity. Therefore, in order to reduce uncertainties in the decadal predictions and to enhance reliability of the IPCC assessment reports, multi-model ensemble predictions are needed in addition to an ensemble hindcast by each climate model.

The MIROC climate model (Model for Interdisciplinary Research on Climate) has been developed at the Atmosphere and Ocean Research Institute, the University of Tokyo, National Institute for Environmental Studies, and Japan Agency for Marine-Earth Science and Technology. Both MIROC $3 \mathrm{~m}$ with a medium resolution and the high resolution version MIROC3h participated in AR4. For the AR5, we have developed new versions of MIROC, namely MIROC4h and MIROC5. The performance of MIROC4h and MIROC5 in the control runs under fixed external forcing is much better than that of the older versions in terms of climatologies and interannual variabilities (Watanabe et al. 2010; Sakamoto et al. 2011).

It is expected that the improved performance in the control runs might lead to higher prediction skills if initialization is done properly. Through many trials and errors in preliminary experiments of data assimilation and decadal prediction, we have established a system that initializes the climate models for decadal predictions. By using our initialization method, model climate drifts are suppressed during predictions and decadal predictabilities for several specific phenomena have been reported based on the output of the decadal hindcast experiments using MIROC (e.g., Mochizuki et al. 2010, 2011; Chikamoto et al. 2011ab; Yasunaka et al. 2011).

The present paper is a description of the initialization method of the MIROC climate models for the IPCC AR5 and CMIP5. Also the results of oceanic hydrographic data assimilation experiments in order to initialize the climate models are described along with a concise account of forecast skill in the decadal climate predictions. We verify whether changes in assimilated oceanic variables on a decadal timescale are correlated with the observations and examine atmospheric responses to the ocean variations. Also the reproducibility of internal climate variations, such as the PDO and the AMO, is investigated in comparison with the observations. Regarding the reproducibility of regional oceanographic events, we examine decadal modulations of eddy activity, focusing on the Kuroshio-Oyashio confluence zone in the western North Pacific. Finally, we show an overview of skills of the initialized hindcast experiments, and summarize the present results.

At this stage, the decadal hindcast and forecast experiments using MIROC3m, MIROC4h, and MIROC5 have been completed. Currently, members of our modelling group and user community are trying to identify what phenomena are predicable in the MIROC experiments, and to address the reasons why these are predictable. Products from these experiments will also be used for quantitative assessment of changes in regional climate, extreme weather events, and marine ecosystem variations.

\section{Climate models and procedure for initialization}

\subsection{Brief descriptions on the MIROC climate models}

The climate models used for decadal predictions are MIROC3m, MIROC4h, and MIROC5. The latter two models are official models for the AR5.

MIROC3m is a coupled model which contributed to IPCC AR4. The resolution of the atmo- 
spheric component is a T42 spectral truncation with 20 vertical layers and that of the oceanic component is $1.4^{\circ}$ in the zonal and $0.56^{\circ}-1.4^{\circ}$ in the meridional directions, respectively, with 43 vertical layers. A control experiment with fixed external forcing at the pre-industrial level in 1850 and a set of the 20th century runs with external forcing based on observations from 1850 to 2000 are conducted. Hereafter, the 20th century run is called the 20C3M run. There are ten ensemble members for the 20C3M run. Further details of MIROC $3 \mathrm{~m}$ are described in K-1 model developers (2004) and Nozawa et al. (2005). MIROC3m was also used for the preliminary decadal hindcast experiments of Mochizuki et al. (2010).

MIROC4h has the same physical and dynamical components of the atmospheric model as a highresolution version of MIROC3m (namely, MIROC3h) used for the IPCC AR4 (K-1 model developers 2004), but the horizontal resolution of the atmospheric component is twice as high in MIROC4h with a T213 spectral truncation compared to MIROC3h with a resolution of T106. The number of vertical levels is 56 using the sigma coordinate system. The oceanic component is mostly the same as that of MIROC $3 \mathrm{~h}$ and it has a so-called eddy-permitting horizontal resolution $\left(1 / 4^{\circ}\right.$ in long. and $1 / 6^{\circ}$ in lat.). The spherical coordinate system of the ocean model is rotated and the north pole of the coordinate system is placed at $77^{\circ} \mathrm{N}, 50^{\circ} \mathrm{W}$ on Greenland. The number of vertical levels is 48, including a bottom boundary layer model. A control experiment with fixed external forcing at the level of that in 1950 and a set of the 20C3M runs with changing external forcing from 1950 to 2005 are conducted. There are three ensemble members for the 20C3M run. The model climatology, interannual variability of the El Niño Southern Oscillation (ENSO) and related teleconnection patterns, and regional phenomena such as coastal upwelling in MIROC4h are better represented than in MIROC3h. Further detailed descriptions of the model configurations and its performance are summarized in Sakamoto et al. (2011, this issue).

MIROC5 has updated and newly-developed parameterizations in both of the atmospheric and oceanic components, including a cumulus convection scheme (Chikira and Sugiyama 2009), a prognostic large-scale condensation scheme (Watanabe et al. 2009), a radiative transfer scheme (Sekiguchi and Nakajima 2008), a land surface model (Takata et al. 2003; Yamazaki et al. 2009), a multi-category sea-ice model (Komuro et al. 2011) and a highly accurate tracer transport algorithm (Tatebe and Hasumi 2010). The resolution of the atmospheric component is a T85 spectral truncation with 40 levels in the vertical, and that of the oceanic component is $1.4^{\circ}$ in the zonal, $0.5^{\circ}-1.4^{\circ}$ in the meridional directions, respectively, and 50 vertical layers. The ocean model is formulated on generalized curvilinear horizontal coordinates, and the two coordinate singularities are placed at $80^{\circ} \mathrm{N}, 40^{\circ} \mathrm{W}$ on Greenland and $80^{\circ} \mathrm{S}, 40^{\circ} \mathrm{W}$ on Antarctica. A control experiment with fixed external forcing at the preindustrial level in 1850 and a set of the 20C3M runs with external forcing based on observations from 1850 to 2005 are conducted. There are three ensemble members for the 20C3M run. In MIROC5, climatological features of zonal-mean atmospheric fields, distribution of precipitation, and the equatorial ocean are considerably better than those of MIROC $3 \mathrm{~m}$. Also, the amplitude and periodicity of ENSO are much improved. See Watanabe et al. (2010) for further detailed descriptions.

\subsection{Procedure for initializing the coupled models}

For decadal climate predictions, signals that isolated and conserved in slowly-varying ocean serve as memories of the climate system. Therefore, there is a great advantage to the initialization of the ocean state in the climate model. No atmospheric variables are constrained by observations in this study.

In the experiments for initializing the climate models, an incremental analysis update (IAU) scheme originally developed by Bloom et al. (1996) and modified by Huang et al. (2002) is used to assimilate observed historical ocean temperature and salinity data with an analysis interval $(\tau)$ of one day. For the time integration from $t=0$ to $t=\tau$, the governing equation including a correction term for temperature and salinity $(X)$ in the IAU is written as

$$
\frac{D X}{D t}=F+D i f+\frac{\alpha}{\tau} \Delta X^{a},
$$

where $X^{a}$ is the analysis, $F$ the surface flux term, and Dif is the diffusion term, respectively. The last term on the right hand side of Eq. (1) is the correction term and this term is held constant during the analysis interval. The analysis increment of Huang et al. (2002), $\Delta X^{a}=X^{a}(0)-X(0)$, is calculated from the analysis and the model first guess at 
$t=0$. The increment given to the model is multiplied by a constant $\alpha$. How to determine $\alpha$ is explained later.

The ocean hydrographic data used for the assimilation are the update version of the global objective analysis of Ishii and Kimoto (2009), who removed biases in the temperature data measured by expendable and mechanical bathythermographs. In the experiments with MIROC3m, an older version of the analysis (Ishii et al. 2006) was used because the latest version was not available at that time. The horizontal resolution of the analysis is $1^{\circ}$, and 33 vertical levels from the surface to $3000 \mathrm{~m}$ are placed at the standard depths of the World Ocean Atlas (e.g., Levitus and Boyer 1994). The monthly hydrographic data are linearly interpolated to form daily data. In computing an analysis increment, its magnitude is set as to be less than the temporal rate of change of tracers for a day at most of the grid points in the model by the constant $\alpha$. In all of the experiments, $\alpha$ is set as 0.025 . Corresponding magnitude of the analysis increment of SST takes its maximum of $1.0 \times 10^{-6} \mathrm{~K} \mathrm{~s}^{-1}$ at the most.

We use anomaly data assimilation to initialize the climate models for the decadal predictions. In the anomaly assimilation, only monthly anomalies with respect to monthly climatology are assimilated. This treatment helps to prevent model climate drifts during predictions. The model monthly climatology of MIROC4h and MIROC5 are calculated using the outputs of the 20C3M runs from 1961 to 2000. In MIROC3m, the outputs of the 20C3M runs from 1961 to 1990 are used. The time period used in defining observed climatology in the anomaly assimilation is consistent with that for the individual model climatology. The observed anomalies are assimilated into the ocean models at depths between the sea surface and $3000 \mathrm{~m}$ in MIROC4h and MIROC5 and between the sea surface and $700 \mathrm{~m}$ in MIROC3m. Similar 'anomaly assimilation' or 'anomaly initialization' is also used in Smith et al. (2007), Keenlyside et al. (2008) and Pohlmann et al. (2009), for example. Although there is no observational constraint below $3000 \mathrm{~m}$ depth in MIROC4h and MIROC5 or below $700 \mathrm{~m}$ depths in MIROC3m, remarkable gaps of analysis increments around the depths in the vertical direction are not found owing to sufficiently small increments at these depths.

The sea-ice data assimilation is not adopted in the present experiments. In addition, on a model grid point adjacent to observed or model grid points covered by sea ice within $10^{\circ}$ in latitude, observed anomalies of hydrographic data are assimilated weakly as a linear function of the distance from the nearest sea ice grid. No observational constraint is given at any sea ice grid points. This is because the temperature and salinity on a grid point near sea ice and below sea ice are considered to be determined by the complex processes of sea ice formation and melting.

In MIROC4h, the resolution of the ocean model is in the eddy-permitting regime. An additional procedure explained below is performed in order to prevent high-frequency oceanic eddies from being damped by observational constraints. Firstly, monthly anomalies on the fine resolution model are calculated, and they are then mapped onto the objective analysis coarse grid of the temperature and salinity observations (Figs. 1a and 1b). To ob- (a)

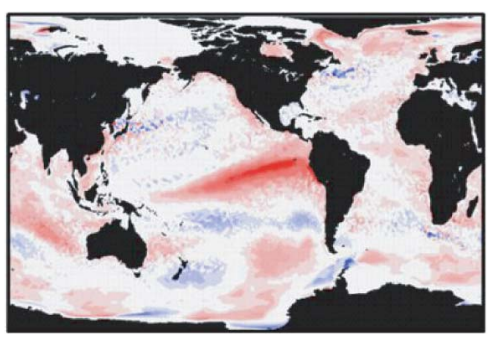

(b)

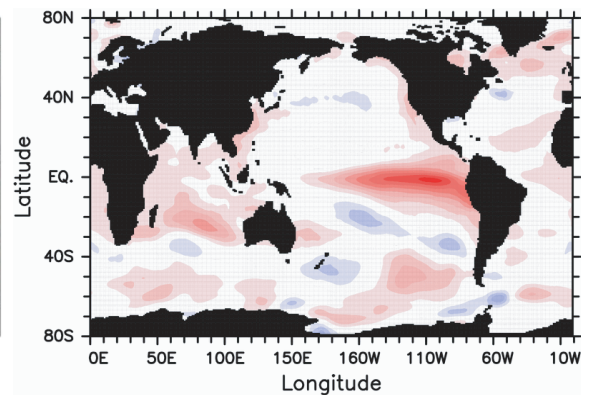

(c)

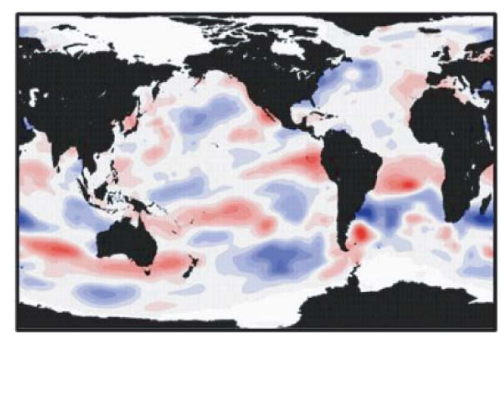

Fig. 1. Schematic of the assimilation procedure for MIROC4h. (a) Temperature anomalies on the original model grid on a given day, (b) those on the analysis grid after spatial interpolation and smoothing, and (c) analysis increments on the model grid. 
tain values on the coarse grid, values of the surrounding points on the fine grid are averaged. This averaging manipulation acts as a spatial smoother to reduce variances of eddies in the model field. Then, a spatial running-mean filter is applied to anomalies on the observation grid for further reduction of eddy variances. The window widths of the filter are $3^{\circ}-11^{\circ}$ in the zonal and $3^{\circ}-5^{\circ}$ in the meridional directions, becoming larger from the surface to $3000 \mathrm{~m}$. To eliminate the zonally elongated structures associated with the deep ocean inertia gravity waves reported by Komori et al. (2008), the zonal window width is larger than the meridional width at greater depths. Secondly, the analysis increments on the observation grid are computed. Finally, the analysis increments are linearly interpolated onto the model grid (Fig. 1c). Following these procedures, oceanic eddies can be generated and decay in response to assimilated background currents and hydrographic structures on larger spatial scales, as described in Section 3.3 .

The analysis increments are added to the governing equations for temperature and salinity as a constant forcing term during the analysis interval. In MIROC $3 \mathrm{~m}$, analysis increments at each vertical level are modified by adding a small constant value so that the global integrals of the increments will be conserved at each level. Via this method, the global supply of heat and salt to the model by the data assimilation can be minimized. This allows separation of signals of internal variability from the global warming trend in the global mean variables by comparison with those of the 20C3M runs. However, such a modification of the analysis increment is not included in the data assimilation experiments with MIROC4h and MIROC5.

In order to adapt model internal variations to the observations gradually at the beginning of the data assimilation, an additional weight that controls the magnitude of the analysis increment, similar to $\alpha$ in Eq. (2), is introduced in the MIROC4h and MIROC5 experiments. The weight is zero at the start date of the assimilation (1950 for MIROC4h and 1945 for MIROC5), and it is linearly increased to unity on Dec. 31 1960. After this date, the weight is maintained at unity.

The assimilation runs are conducted from Jan. 1950 to Dec. 2007 with MIROC4h and from Jan. 1945 to Dec. 2007 with MIROC3m and MIROC5, using initial conditions of the atmosphere and ocean states obtained from the 20C3M runs at the start dates (see Fig. 2). The numbers of ensemble members in the assimilation runs are one

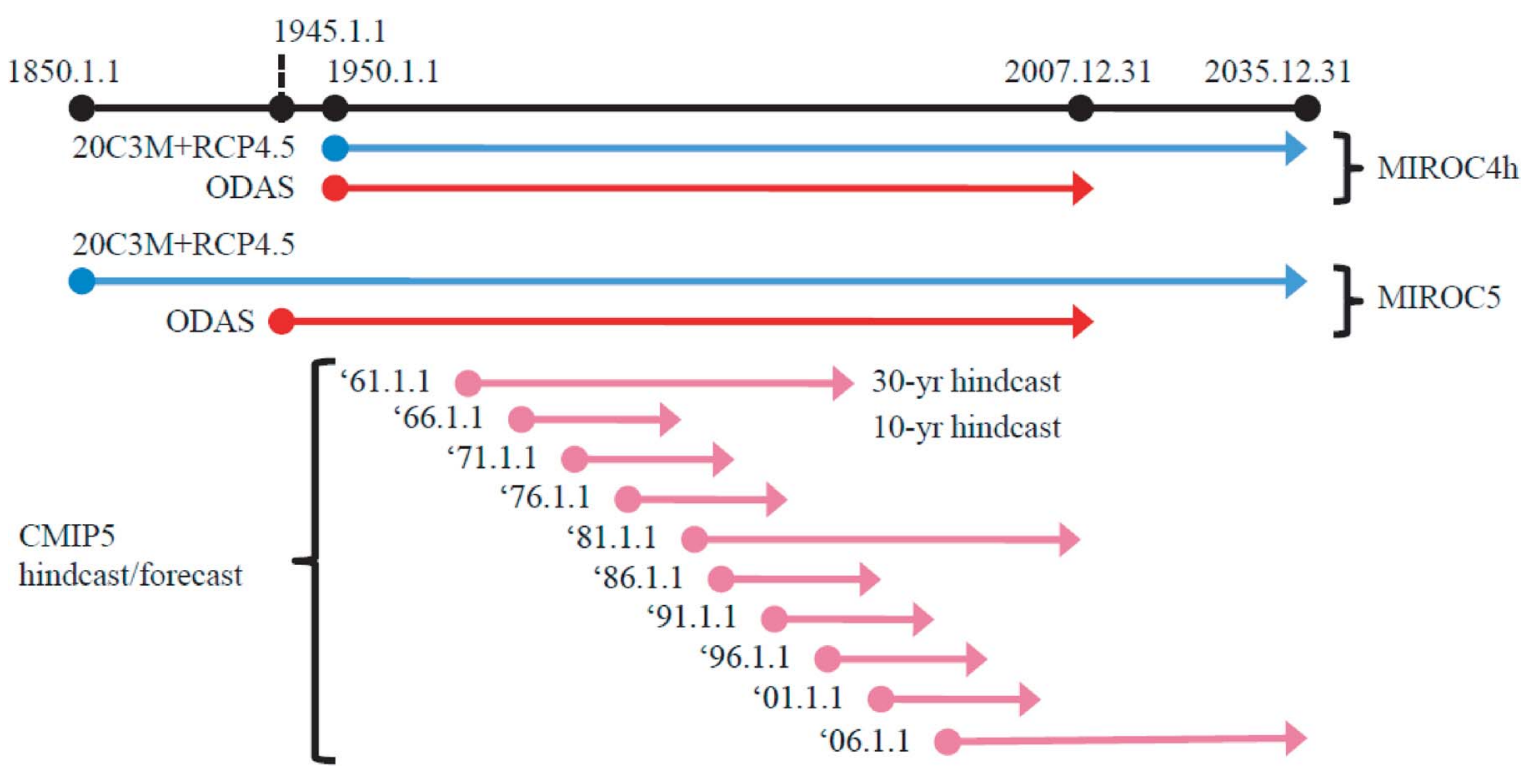

Fig. 2. Experimental design based on the CMIP5 protocol. 20C3M+RCP4.5 (blue arrows) stands for the 20 th century runs and scenario runs with the representative concentration pathway 4.5 , which is one of the emission scenarios, and ODAS (red arrows) indicates ocean data assimilation runs. The long and short pink arrows denote the 30 - and 10-yr-long predictions, respectively. 
for MIROC4h, three for MIROC5, and ten for MIROC $3 \mathrm{~m}$.

For ensemble hindcast and forecast experiments of MIROC4h and MIROC5, the lagged average forecast (LAF) method is used. Initial conditions for the LAF method are prepared on July 1 , October 1 in the year before the designated year of the CMIP5 protocol and January 1 of the designated year (every five years from 1961 to 2006). For the experiments using MIROC3m, initial conditions are prepared every 5 years on July 1 from 1960 to 2005. In this case, the LAF method is not used, since ten assimilation runs are available. The numbers of ensemble members of the hindcast/forecast experiments are three for MIROC4h, nine for MIROC5, and ten for MIROC3m.

In all the experiments of the data assimilation and decadal prediction, the climate models are forced with prescribed GHG concentrations and volcanic aerosols as done in the 20C3M runs, following the CMIP5 protocol.

\section{Results}

\subsection{Overview of the assimilated ocean model and associated atmospheric variables}

Firstly, we verify that decadal changes in the assimilated oceanic variables are correlated with the observations, and we examine how atmospheric variables respond to changes in the ocean. Timeseries of the global mean sea surface temperature (SST) anomalies and the global mean surface air temperature (SAT) anomalies relative to monthly climatology are shown in Fig. 3. For verification of the assimilation runs, the objective analysis of Ishii and Kimoto (2009) is used as the ocean observation unless otherwise specified. For the observed SAT data, the NCEP/NCAR reanalysis (Kalnay et al. 1996) is used. The rising trends of the global mean SST after the mid-1970s due to the increase in anthropogenic GHGs are represented in the assimilation runs and the 20C3M runs (blue lines) among all of the MIROC runs, consistent with the observations. Corresponding to the assimilated SST variations, the global mean SAT also shows the rising trends through the changes in air-sea fluxes. After 2000, the warming trend is found to slow down in the observations and the assimilation runs of MIROC4h and MIROC5, while it is absent in the assimilation runs of MIROC $3 \mathrm{~m}$. This is because the global integrals of analysis increments for temperature and salinity are adjusted to zero in MIROC3m, as described in Section 2.2. As for interannual-to-decadal scale changes, phases of internal variations of the global mean SST and SAT of the 20C3M runs are not synchronized amongst members, while those of the assimilation runs are in agreement with one another. Note that agreement in the timing of abrupt temperature decreases in the $20 \mathrm{C} 3 \mathrm{M}$ runs are due to volcanic eruptions, for example, the Mt. Pinatubo eruption in 1991.

Figures 4 and 5 show maps of correlation coefficients and root-mean-squared (RMS) errors between the observations and the assimilation runs for 5-yr-mean SST anomalies and 5-yr-mean ocean temperature anomalies averaged in the upper $300 \mathrm{~m}$ (VAT300) from 1961 to 2000. In Fig. 5, areas where ratios of RMS errors to observed RMS amplitudes are larger than unity are stippled. Before calculating the observed RMS amplitudes, anomalies are detrended to take into account internal variations only. Here, to examine how model variables are correlated with the observations on a decadal timescale and a centennial timescale corresponding to the global warming, anomalies in 5-yrmean fields are used. In all of the assimilation runs, the correlation coefficients for SST and VAT300 are generally larger than 0.8 , and the RMS errors are smaller than the observed RMS amplitudes in the global domain, apart from regions of sea-ice formation where the observational constraints are weak or absent. In regions of the western boundary currents and the Antarctic Circumpolar Current $(\mathrm{ACC})$, relatively small correlation coefficients with large RMS errors are found. We speculate that differences in the climatological depths and distributions of the thermocline between the models and the observations may disturb dynamic adjustments of the model oceans to the assimilated temperature anomalies. This may lead to the relatively small correlation coefficients and large RMS errors. To the south of Central America and around Hawaii, there are local minima of correlation coefficients and local maxima of RMS errors of SST, which might be caused by regional coastal upwelling induced by strong surface winds. In VAT300, these discrepancies between the assimilation runs and the observations are also found around the equator. One possible reason for this is that strong vertical advection resulting from equatorial upwelling overcome the constraint of the ocean data assimilation.

Regarding atmospheric variables that are not 

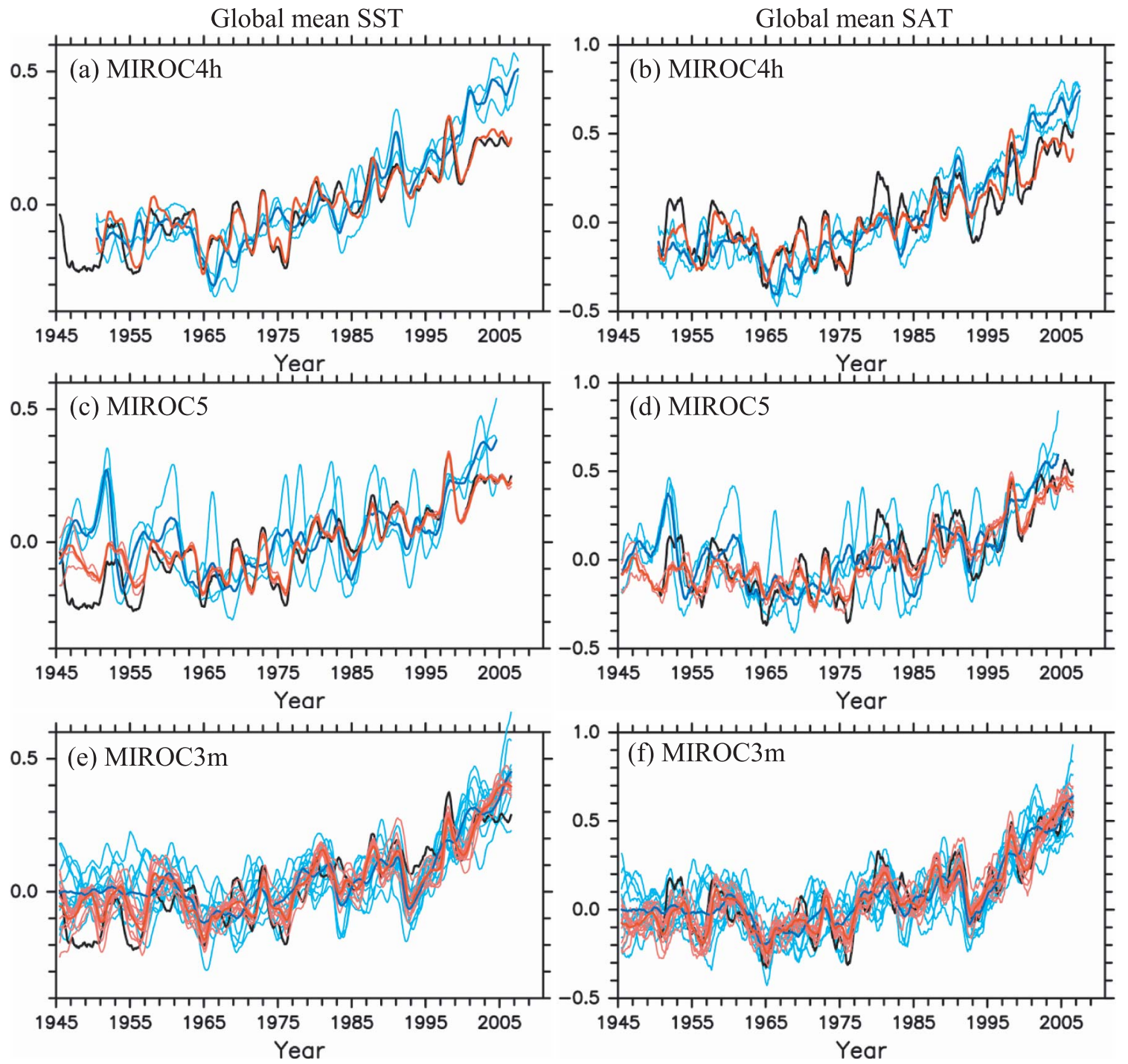

Fig. 3. Time-series of global mean sea surface temperature and surface air temperature anomalies (unit; K) relative to the climatological mean values. A 1-yr running-mean filter is applied. The black line denotes the observation, and the red and blue lines denote the assimilation runs and the 20C3M runs, respectively. The thick red and blues lines are the ensemble means of the assimilation runs and the 20C $3 \mathrm{M}$ runs, respectively.

constrained by observations directly, 5-yr-mean sea level pressure (SLP) anomalies in the climate models are highly correlated with the observations in the tropics and the subtropics over the oceans (left panels in Fig. 6), and RMS errors of SLP are smaller than the observed RMS amplitudes (left panels in Fig. 7). Here, the observation data for SLP are from the NCEP/NCAR reanalysis (Kalnay et al. 1996). On the other hand, the SLP anomalies in the assimilation runs are poorly corre- lated with the observations in mid and high latitudes, with large RMS errors. In particular, these discrepancies between the assimilation runs and the observations are remarkable along the Gulf Stream and the ACC. Correlation coefficients and RMS errors of SAT (right panels in Fig. 6) reflect those of SST. Thus, SAT variations are more synchronized with the observations over the oceans, compared with SLP.

Over the land, SLP and SAT in the models are 
(a) SST, MIROC4h

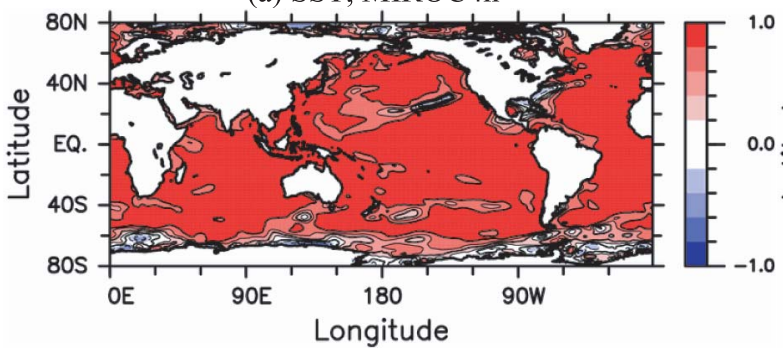

(c) SST, MIROC5

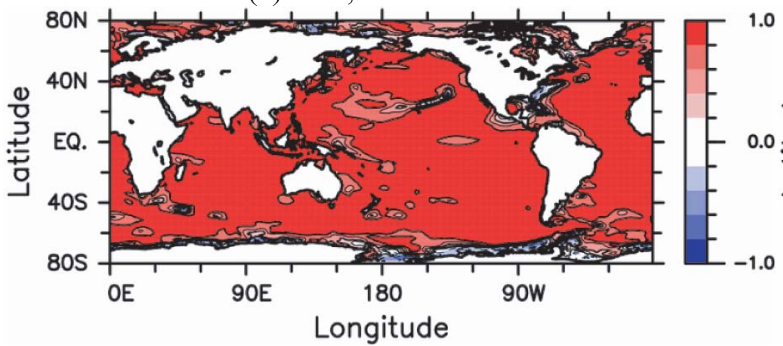

(e) SST, MIROC3m

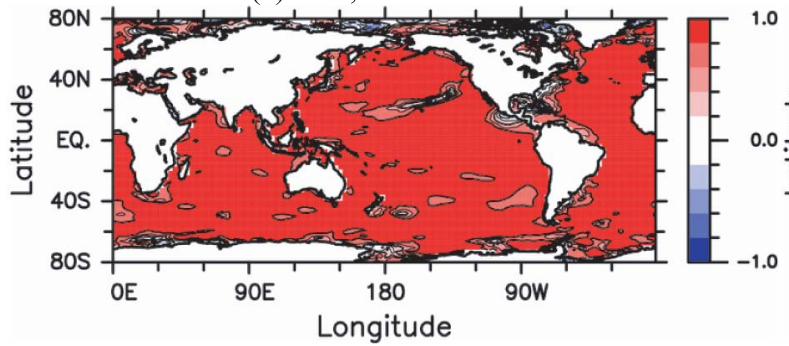

(b) VAT300, MIROC4h

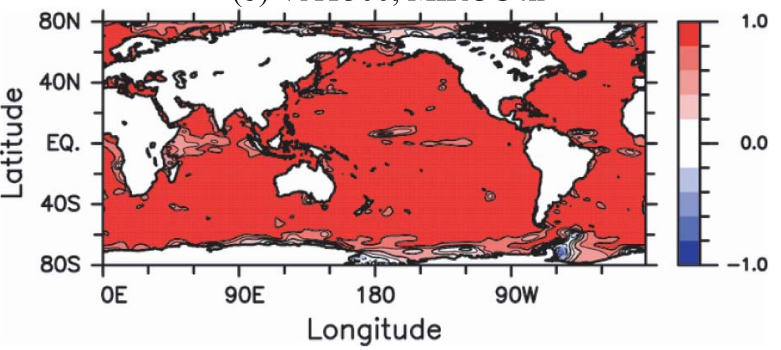

(d) VAT300, MIROC5

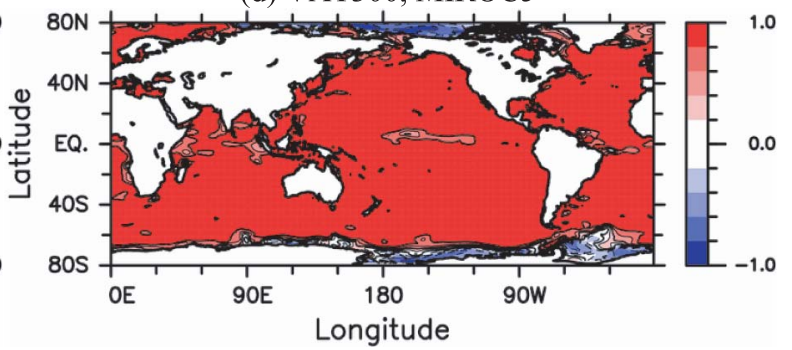

(f) VAT300, MIROC3m

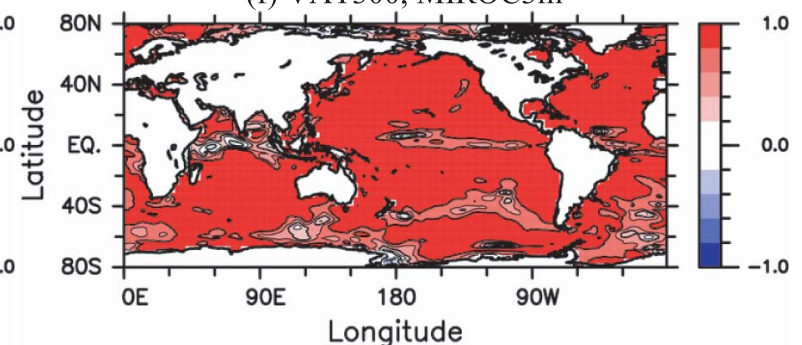

Fig. 4. Maps of correlation coefficients between the observations and the assimilation runs for 5-yr-mean sea surface temperature anomalies (SST; left) and 5-yr-mean ocean temperature anomalies averaged in the upper $300 \mathrm{~m}$ (VAT300; right) over the period from 1961 to 2000.

weakly or negatively correlated with the observations, depending on the model. In the maps of SLP shown in Figs. 6 and 7, negative correlations over the northern part of Eurasian continent, the Mediterranean, and Canada are remarkable in MIROC5, and the corresponding RMS errors are also significant. Similar tendencies are found also in MIROC4h and MIROC3m, but the RMS errors in MIROC $3 \mathrm{~m}$ are smaller than those in the other models. In the maps of SAT, there are distinct negative correlations over the Australian and South American continents in all the assimilation runs, and large RMS errors are obvious there. The SAT anomalies over land are not much affected by ocean temperatures, and are governed primarily by land-air interactions. For better decadal predictions, initializing land surfaces and improvement of the land surface model are necessary.

\section{$3.2 P D O$ and $A M O$}

Global mean SAT and SST are representative variables used in discussing decadal climate changes. These reflect the internal climate variations that have spatial structures in amplitude and phase and the forced global warming signals. In order to make better decadal predictions both regionally and globally, reproducing internal variations in a climate model is important. The performance of intrinsic variations in MIROC4h and MIROC5 are summarized in Watanabe et al. (2010) and Sakamoto et al. (2011). Here, we examine the predominant decadal climate variations of the PDO and the AMO reproduced by the ocean data assimilation experiments compared with the observations.

Figure 8a shows time-series of the monthly PDO index smoothed with a 1-yr running mean filter. Correlation and regression coefficients between the 
(a) SST, MIROC4h

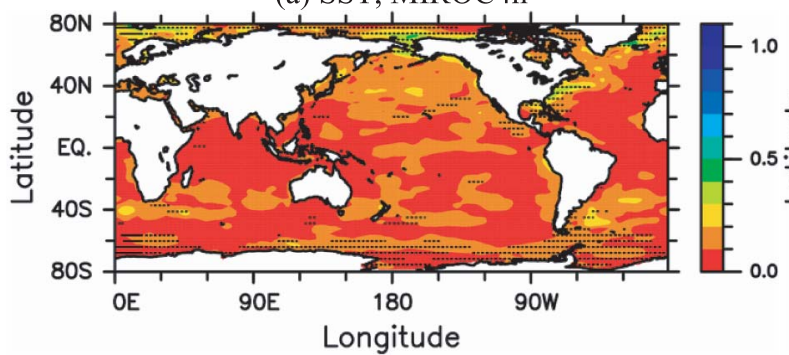

(c) SST, MIROC5

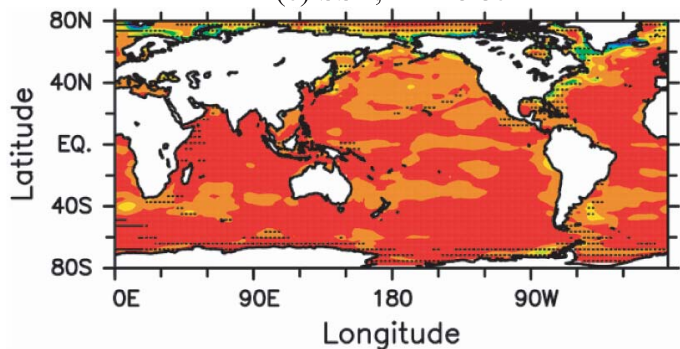

(e) SST, MIROC3m
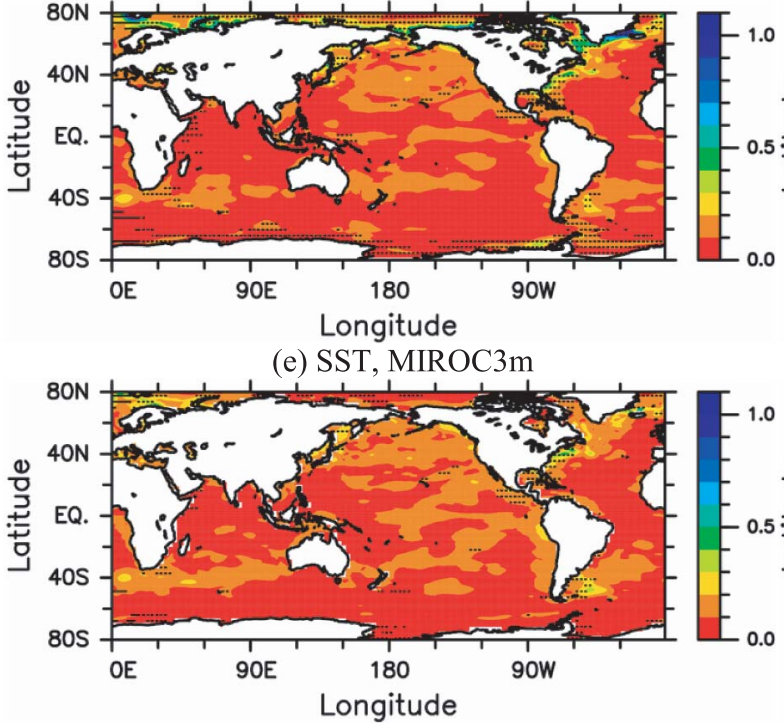

(b) VAT300, MIROC4h

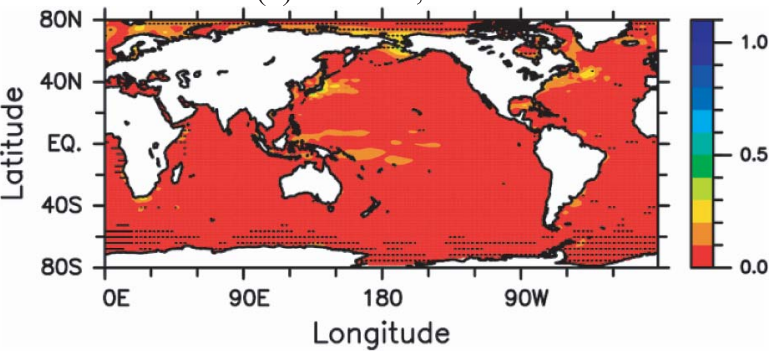

(d) VAT300, MIROC5

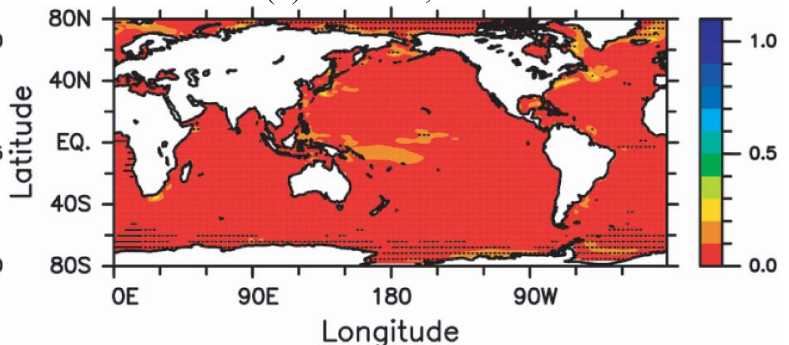

(f) VAT300, MIROC3m

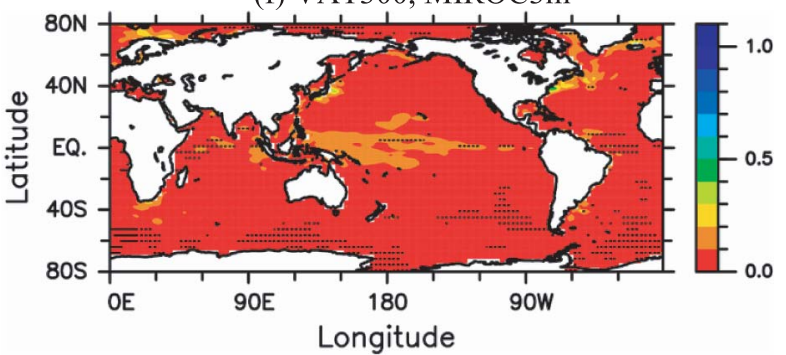

Fig. 5. Same as Fig. 4, but for RMS errors of SST and VAT300 (unit; K) between the assimilation runs and the observations. Areas where ratios of RMS errors to observed RMS amplitudes are larger than unity are stippled. Before calculating the observed RMS amplitudes, anomalies are detrended to take into account internal variations only.

index and anomalies of SAT, SLP, and precipitation are shown in Fig. 9. Following Mantua et al. (1997), the PDO index is defined as the principal component of detrended monthly SST anomalies in the North Pacific $\left(20^{\circ} \mathrm{N}-65^{\circ} \mathrm{N}\right.$ and $110^{\circ} \mathrm{E}-$ $100^{\circ} \mathrm{W}$ ). CMAP data (Xie and Arkin 1997) are used as the observed precipitation. In the observations, when the PDO is in a positive phase, there are the predominant negative SAT and SLP anomalies in the mid-latitudes of the North Pacific corresponding to strengthening of the Aleutian low, which could be forced remotely by the positive SST anomaly existing simultaneously in the tropics. Positive SAT anomalies are distributed along the west coast of North America and in the Bering Sea. These features of the observed PDO are also represented in all of the MIROC assimilation runs.

Decadal changes of precipitation patterns are also linked with the PDO (e.g., Cayan et al. 2001). As seen in the observations, precipitation in the tropical Pacific increases in the positive PDO phase, while precipitation in the subtropics decreases. In the mid-latitudes, the precipitation increases to the east of the Aleutian low action center and it decreases around the $55^{\circ} \mathrm{N}, 180^{\circ}$. This precipitation pattern in the mid-latitudes results from northward transport of warm and wet air and southward transport of cold and dry air by the strengthening of the Aleutian low. In MIROC4h, these features in the mid-latitudes are well captured. However, this decrease in precipitation is not so clear in MIROC5 and MIROC $3 \mathrm{~m}$, and the increase to the east of the Aleutian low appears weak in MIROC $3 \mathrm{~m}$.

Figure $8 \mathrm{~b}$ shows time-series of the monthly AMO index smoothed with a $1-y r$ running mean filter, and correlation and regression coefficients 
(a) SLP, MIROC4h

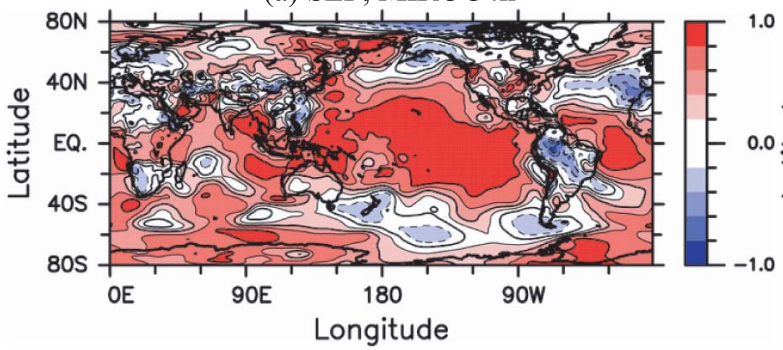

(c) SLP, MIROC5

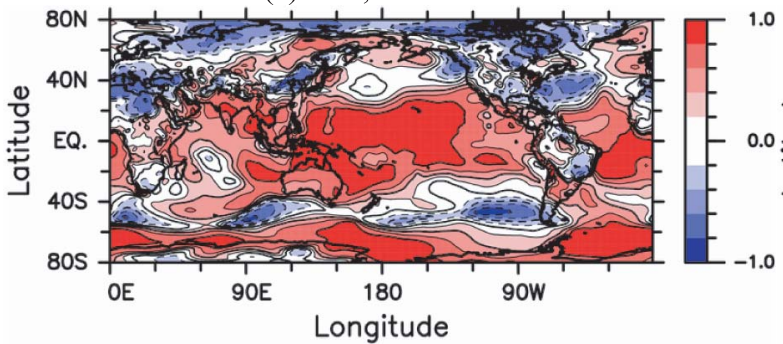

(e) SLP, MIROC $3 \mathrm{~m}$

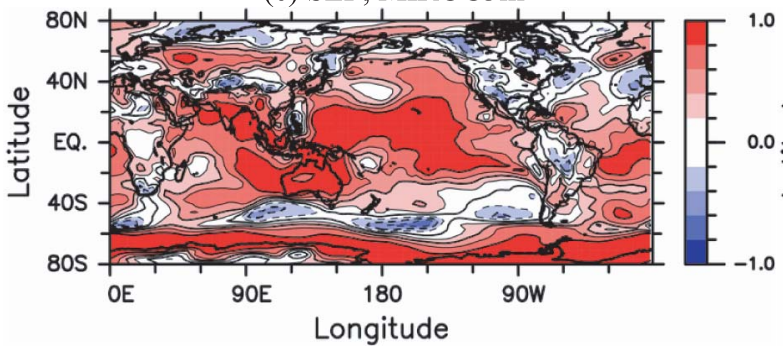

(b) SAT, MIROC4h

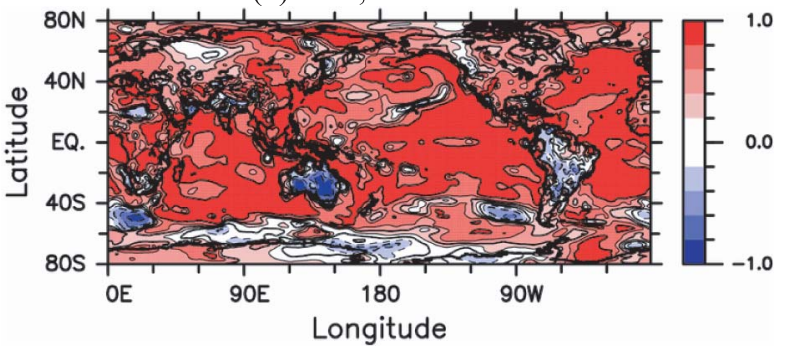

(d) SAT, MIROC5

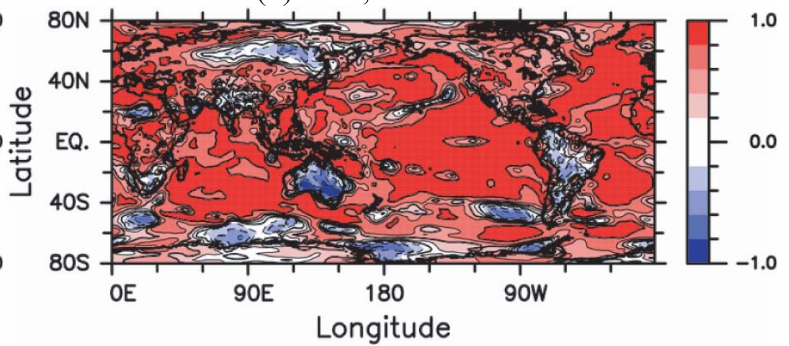

(f) SAT, MIROC $3 \mathrm{~m}$

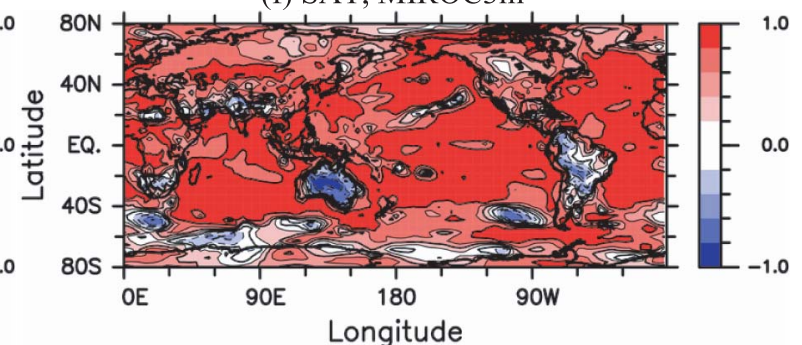

Fig. 6. Same as Fig. 4, but for 5-yr mean sea level pressure anomalies (SLP; left) and surface air temperature anomalies (SAT; right).

between the index and anomalies of SAT, SLP, and precipitation are shown in Fig. 10. Following Enfield et al. (2001), the AMO index is defined as the detrended areal-average of monthly SST anomalies in the North Atlantic Ocean $\left(0^{\circ} \mathrm{N}-70^{\circ} \mathrm{N}\right)$. In the observations, when the AMO index is positive, SAT anomalies around the Labrador Sea and in the tropical North Atlantic $\left(0^{\circ} \mathrm{N}-20^{\circ} \mathrm{N}\right)$ are predominantly positive. Associated with these SAT anomalies, SLP anomalies tend to be negative over the North Atlantic. In the assimilation runs, these patterns of SST and SLP are well simulated, especially in MIROC4h. Over the Eurasian, African, and North American continents, SLP anomalies are negative in a positive AMO phase in the observations. However on these continents, SLP anomalies simulated by the models are not always consistent with the observations.

As for the precipitation pattern of the observations, when the AMO index is positive, decreases in precipitation appears over most of the USA and the northeastern part of Brazil, while increases are found over the northern and eastern parts of Europe and the western part of Africa. The patterns of decreased precipitation are represented in MIROC4h consistently with the observations. In MIROC5, only the decrease over the northeastern part of Brazil is found. Over the North Atlantic Ocean, there are the positive (negative) precipitation anomalies to the south (north) of the Gulf Stream in the observations. There is another pair of positive and negative anomalies around the equator in the Atlantic and Pacific. These precipitation patterns are well represented in MIROC4h and MIROC5, while they are rather indistinctive in MIROC3m, especially in the Gulf Stream region and the equatorial region of the Pacific.

The AMO is considered to be associated with the changes in strength of the AMOC (Sutton and Hudson 2005; Zhang and Delworth 2005). How- 
(a) SLP, MIROC4h

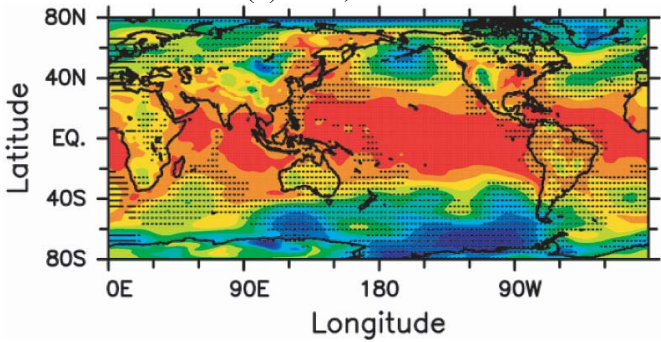

(c) SLP, MIROC5

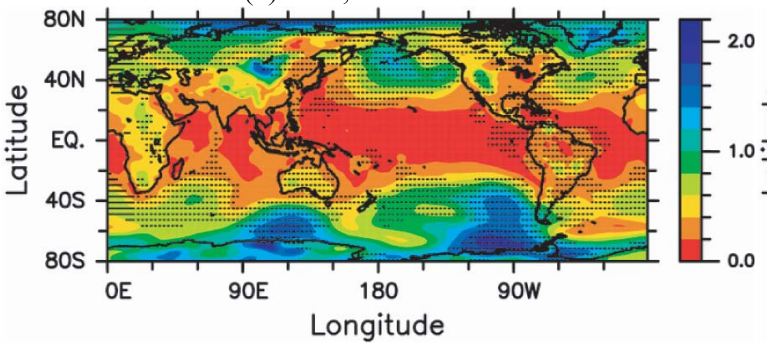

(e) SLP, MIROC3m

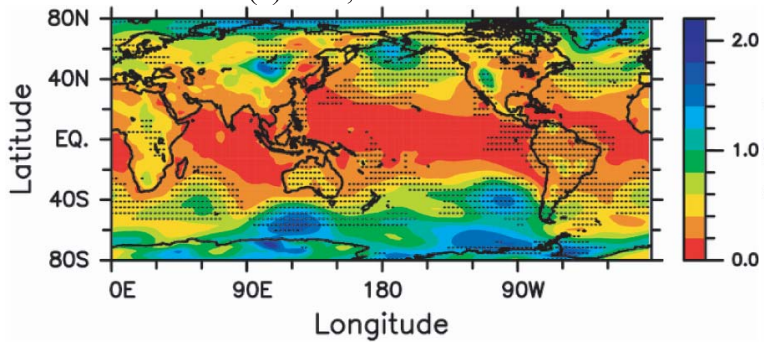

(b) SAT, MIROC4h
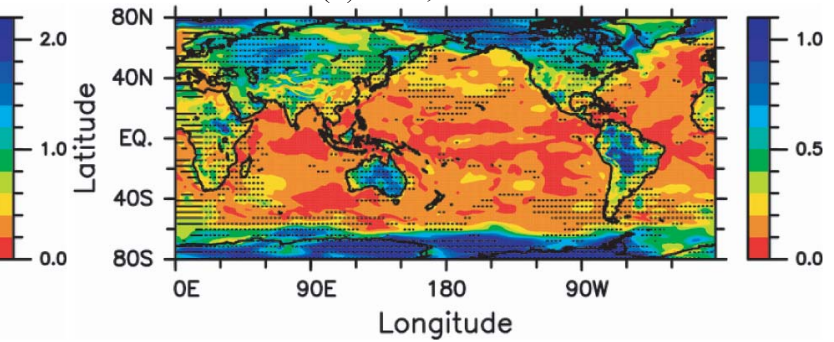

(d) SAT, MIROC5

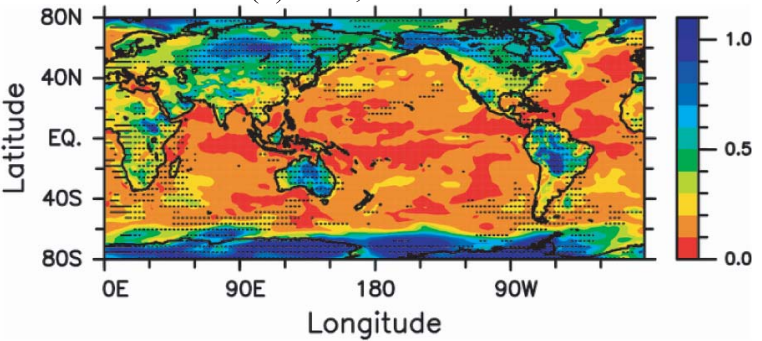

(f) SAT, MIROC3m

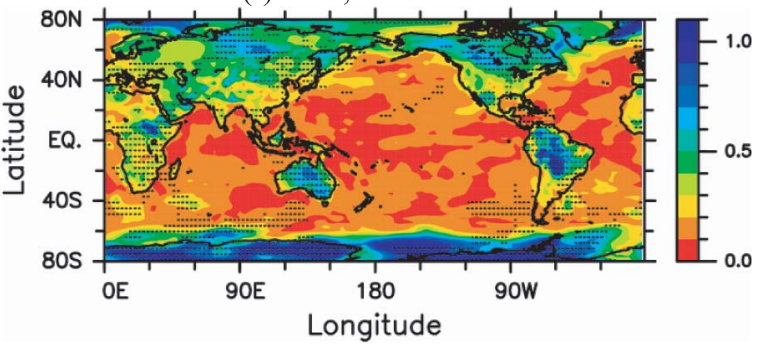

Fig. 7. Same as Fig. 5, but for SLP (hPa; left) and SAT (K; right).

(a)

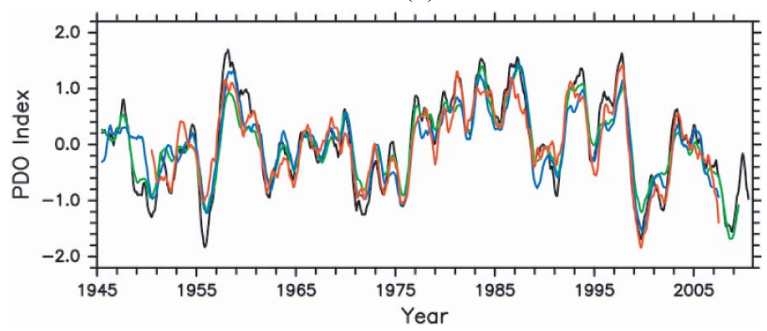

(b)

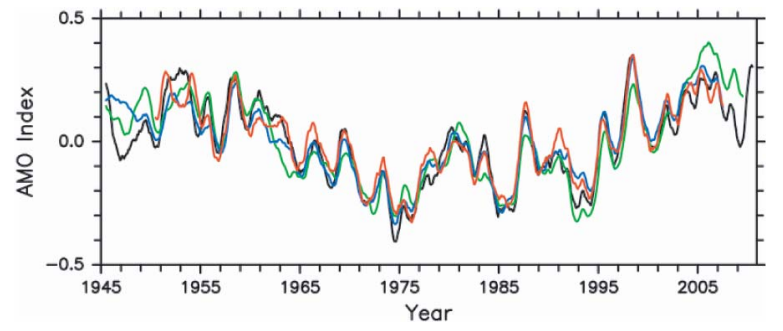

Fig. 8. Time-series of the monthly (a) PDO index and (b) AMO index, smoothed by a 1-yr running-mean filter. The red, blue, green, and black lines denote the results of MIROC4h, MIROC5, MIROC $3 \mathrm{~m}$ and the observation, respectively. Here, the PDO index is defined as the principal component of detrended monthly SST anomalies in the North Pacific $\left(20^{\circ} \mathrm{N}-65^{\circ} \mathrm{N}\right.$ and $\left.110^{\circ} \mathrm{E}-100^{\circ} \mathrm{W}\right)$ following Mantua et al. (1997), and the AMO index is defined as the detrended areal-average of monthly SST anomalies in the North Atlantic Ocean $\left(0^{\circ}-70^{\circ} \mathrm{N}\right)$ following Enfield et al. (2001).

ever, it is noted that the AMOC in our models does not show clear decadal variations and it changes on interannual timescale with amplitude of $2 \mathrm{~Sv}$ $\left(1 \mathrm{~Sv}=10^{6} \mathrm{~m}^{3} \mathrm{~s}^{-1}\right)$ at most (not shown).

\subsection{Oceanic mesoscale eddy activity and its decadal scale modulations}

MIROC4h is capable of representing oceanic mesoscale eddies generated from unstable strong 
(a) SAT, Observation

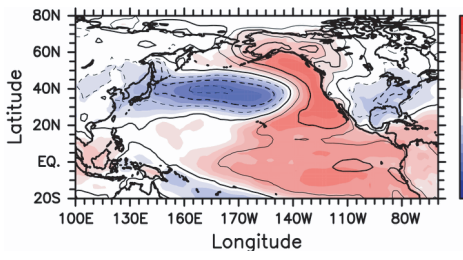

(d) SAT, MIROC4h

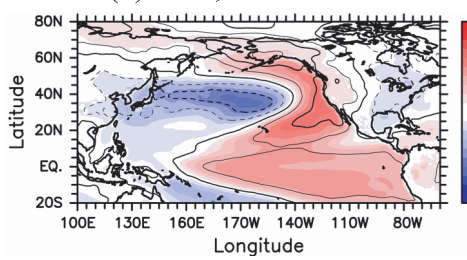

(g) SAT, MIROC5

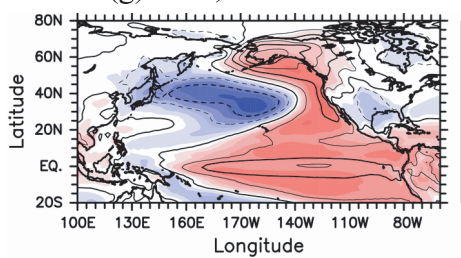

(j) SAT, MIROC $3 \mathrm{~m}$

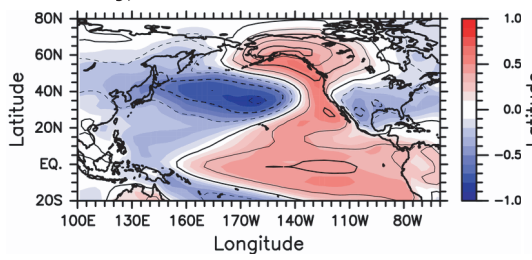

(b) SLP, Observation

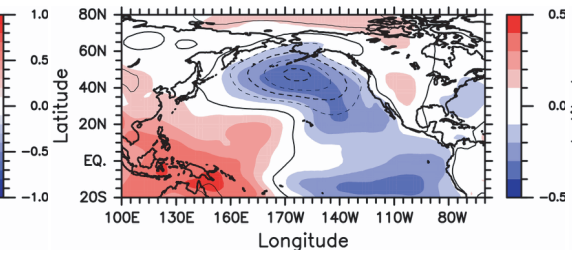

(e) SLP, MIROC4h

(c) Precipitation, Observation

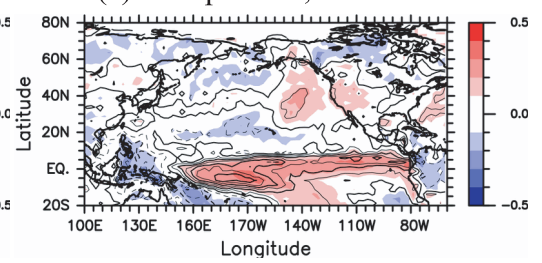

(f) Precipitation, MIROC4h

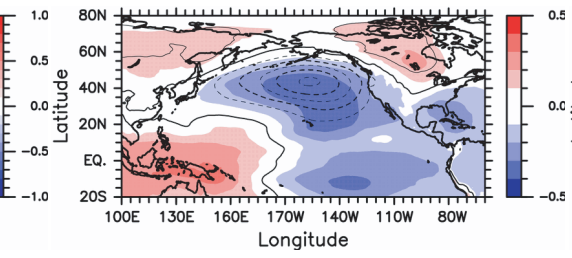

(h) SLP, MIROC5

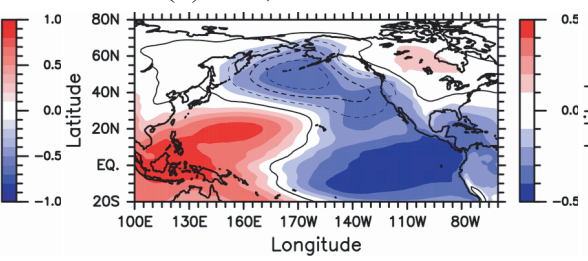

(k) SLP, MIROC3m

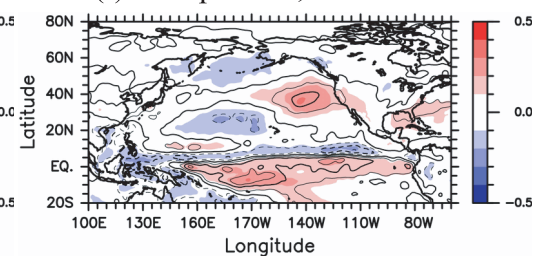

(i) Precipitation, MIROC5

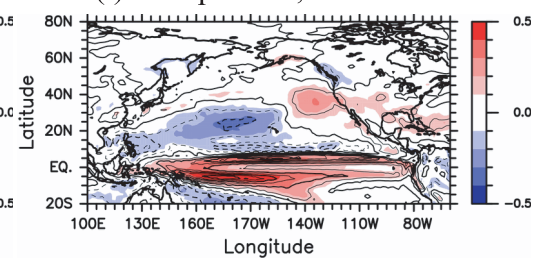

(1) Precipitation, MIROC $3 \mathrm{~m}$
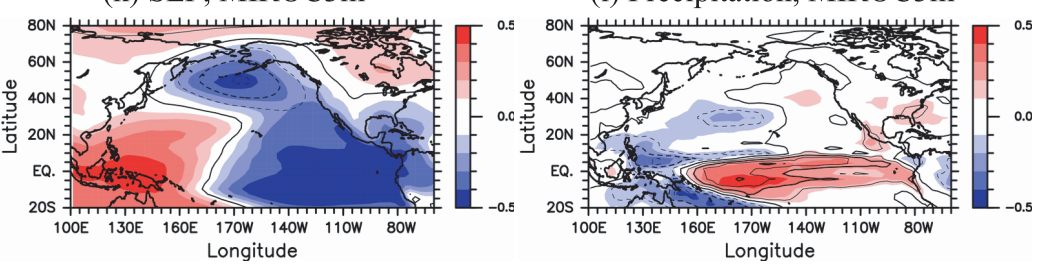

Fig. 9. Correlation (shades) and regression (contours) coefficients between the PDO index and anomalies of SAT (left; contour interval $[\mathrm{CI}]=0.2 \mathrm{~K} \mathrm{~K}^{-1}$ ), SLP (middle; $\mathrm{CI}=0.5 \mathrm{hPa} \mathrm{K}{ }^{-1}$ ), and precipitation (right; $\mathrm{CI}=0.2 \mathrm{~mm} \mathrm{~d}^{-1} \mathrm{~K}^{-1}$ ). Note that a spatial running mean filter with a $1^{\circ}$ window is applied to the precipitation anomalies of MIROC4h for clear representation.

currents and oceanic temperature fronts. Recently, mesoscale eddies have been attracting the interest of oceanographers because they are important in the formation of specific water masses and in ecosystem variations through eddy-induced transports. Using MIROC3h and following the GHGs emission scenarios of the IPCC AR4, Suzuki et al. (2005) reported that the RMS amplitudes of the sea surface height (SSH) anomalies with periods shorter than 3 months increase by acceleration of the Kuroshio Extension under global warming.

Figure 11 shows maps of RMS amplitude of high-pass filtered SSH anomalies in the period from 1996 and 2000. Following Qiu and Chen (2005), variations of SSH anomalies with periods shorter than 300 days are interpreted as being oce- anic eddies. In the present study, we call RMS amplitude of the highpass-filtered SSH anomalies or corresponding eddy kinetic energy (EKE) "eddy activity". The satellite altimeter data supplied by the AVISO/CNES of France are used for the observations. In the results of the assimilation and $20 \mathrm{C} 3 \mathrm{M}$ runs, remarkable eddy activity is found in the Kuroshio-Oyashio confluence zone (KO zone), the Gulf Stream region, the Brazil-Malvinas confluence, the Antarctic Ocean, the Agulhas leakage, etc. In the equatorial region, eddy activity related to the tropical instability waves (e.g., Düeing et al. 1975; Legeckis et al. 1977) is recognized. Regions with large eddy activity are commonly seen in the observations. Eddy activity in the model runs is generally smaller than those in the observations, 
(a) SAT, Observation

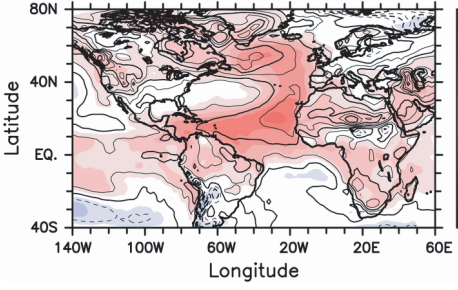

(d) SAT, MIROC4h

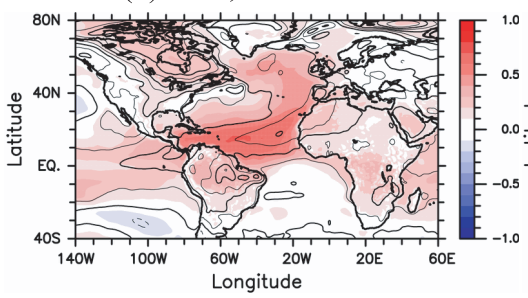

(g) SAT, MIROC5

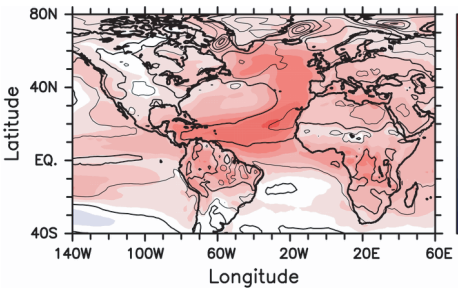

(j) SAT, MIROC3m

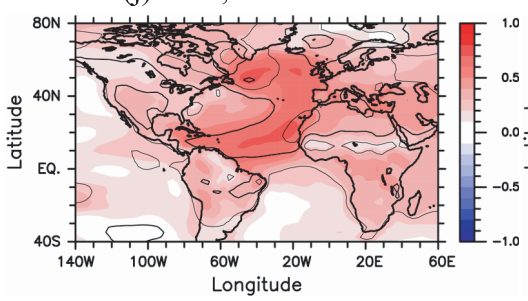

(b) SLP, Observation

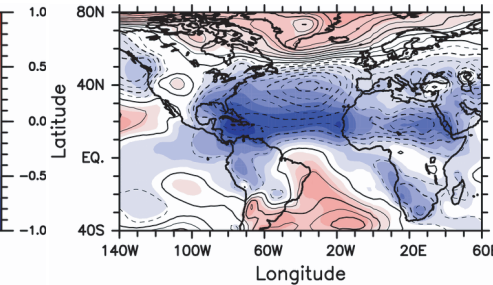

(e) SLP, MIROC4h

(c) Precipitation, Observation

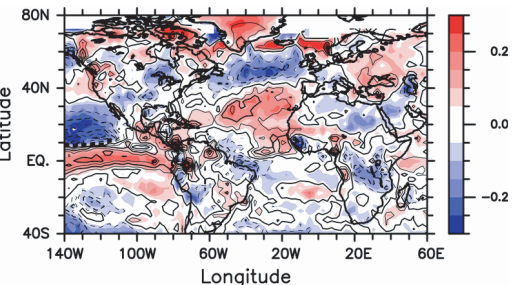

(f) Precipitation, MIROC4h

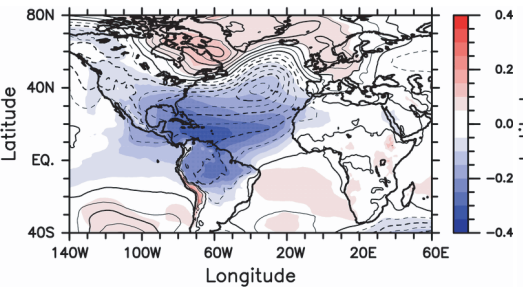

(h) SLP, MIROC5

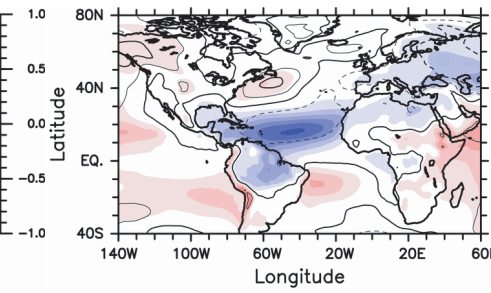

(k) SLP, MIROC $3 \mathrm{~m}$
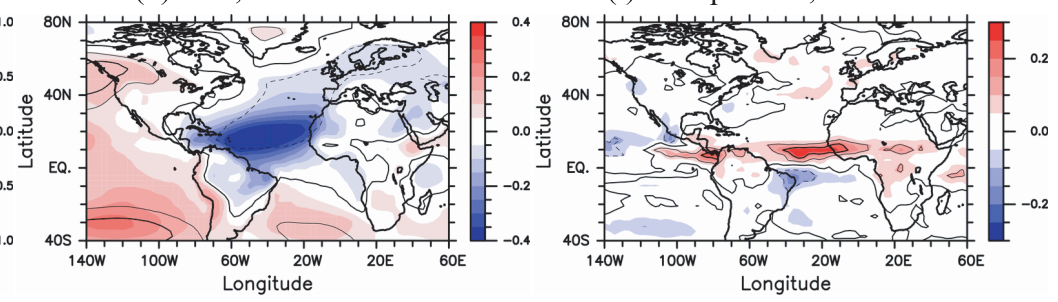

(i) Precipitation, MIROC5

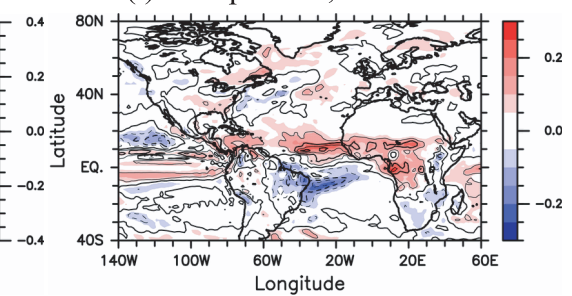

(1) Precipitation, MIROC $3 \mathrm{~m}$

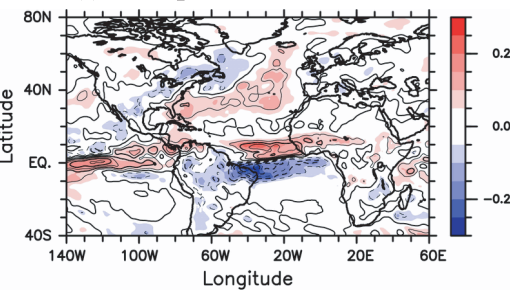

Fig. 10. Correlation (shades) and regression (contours) coefficients between the AMO index and anomalies of SAT (left; contour interval $[\mathrm{CI}]=0.5 \mathrm{~K} \mathrm{~K}^{-1}$ ), SLP (middle; $\mathrm{CI}=0.5 \mathrm{hPa} \mathrm{K} \mathrm{K}^{-1}$ ), and precipitation (right; $\mathrm{CI}=0.5 \mathrm{~mm} \mathrm{~d}^{-1} \mathrm{~K}^{-1}$ ). Note that a spatial running mean filter with a $1^{\circ}$ window is applied to the precipitation anomalies of MIROC4h for clear representation.

particularly along the ACC. This is due to the eddy-permitting, not eddy-resolving, horizontal resolution of the ocean model.

Eddy activity in the assimilation run is comparable with those in the $20 \mathrm{C} 3 \mathrm{M}$ runs. The characteristics of eddies, such as propagation directions and lifetimes, also remain basically the same. Therefore, the data assimilation scheme specified for the eddy-permitting model involves no harmful constraints on eddy activity and works reasonably as expected.

Figure 12 shows time-longitude plots of square root of the observed and modeled EKE averaged in the $\mathrm{KO}$ zone between $32^{\circ} \mathrm{N}$ and $38^{\circ} \mathrm{N}$. EKE is a power of horizontal velocities, and velocity changes in the eddy-permitting ocean model are generally small in comparison with the observations. To show variations of EKE in the model clearly, we use the square root of EKE. The EKE is modulated on a decadal timescale in both the assimilation run and the observation. As reported by Qiu and Chen (2005), the observed EKE level in the upstream Kuroshio Extension to the west of $153^{\circ} \mathrm{E}$ is strengthened in the periods of 1996-2000 and after 2005 while it is weakened in the periods of 1993 1995 and 2001-2004. In the downstream region to 
(a)

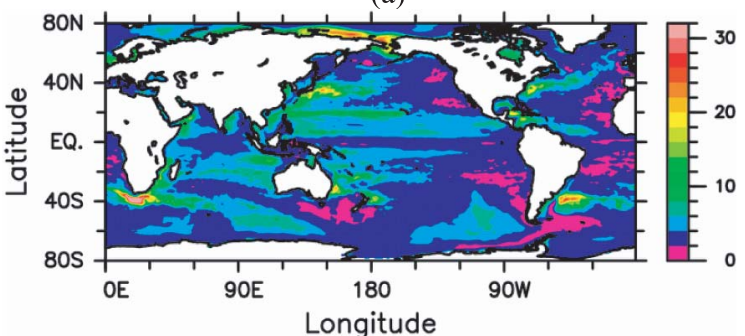

(b)

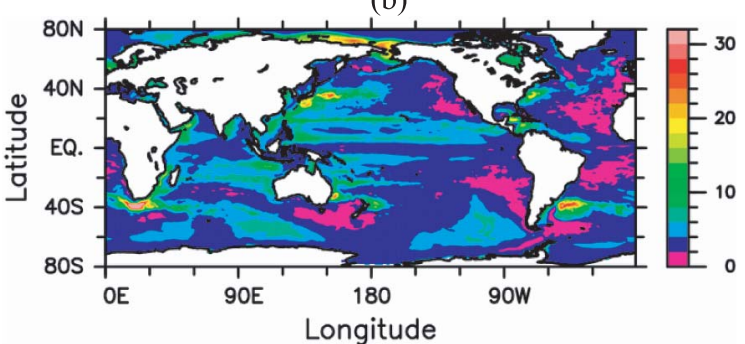

(c)

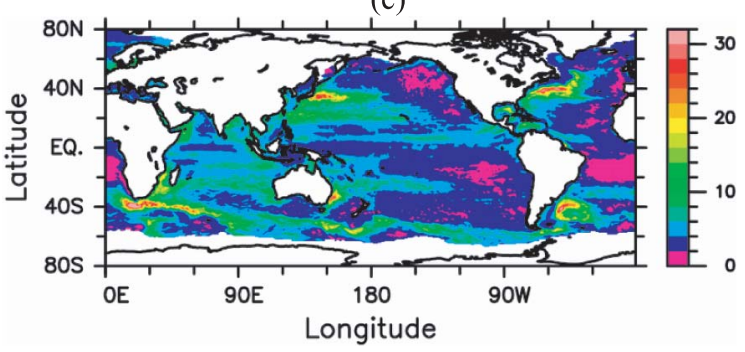

Fig. 11. Maps of root-mean squared amplitude of high-pass filtered (periods shorter than 300 days) sea surface height anomalies (unit; cm) in the period from 1996 and 2000. (a) The MIROC4h assimilation run, (b) the MIROC4h 20C3M runs, and (c) the observations estimated using the satellite altimeter data of the AVISO.

the east of $153^{\circ} \mathrm{E}$, the observed EKE is strengthened in the period of 2001-2005 and is relatively low before 2001. Such modulations of the EKE are consistently represented in the assimilation run, although the model EKE variations are somewhat out of phase by a few years with smaller amplitude than in the observations, especially to the west of $145^{\circ} \mathrm{E}$. In the $20 \mathrm{C} 3 \mathrm{M}$ runs, the modulations are absent, suggesting that these could not be associated with forced variations of global warming and volcanic eruptions. Regarding the basic state, the Kuroshio Extension is strengthened (weakened) in the period of lower (higher) EKE as shown by Qiu and Chen (2005), and these variations are found also in the assimilation run (not shown). It is em- phasized that the modulations of the EKE or eddy activity can be represented if the variations in large-scale hydrographic structures are assimilated properly.

The $\mathrm{KO}$ zone is known as a region of active primary production in the marine ecosystem and for the formation of North Pacific Intermediate Water (e.g., Yasuda et al. 1996; Yasuda 1997) through eddy-induced mixing of cold, fresh, and rich-nutrient water of subarctic origin and warm and saline water of subtropical origin (e.g., Hashioka et al. 2009; Ishikawa and Ishizaki 2009; Sumata et al. 2010). To meet the aim of better simulations and moreover better predictions of marine ecosystem, modulations of eddy activity in numerical models needs to be reproduced realistically.

\subsection{An overview of decadal predictions using MIROC}

We briefly demonstrate results of the hindcast experiments in order to confirm that the procedure for initializing MIROC described in the present manuscript works well for decadal climate predictions. The hindcast experiments are conducted as shown in Fig. 2. Figure 13 shows RMS errors of 5-yr-mean VAT300, SAT, and SLP anomalies between the observations and the initialized hindcast runs. Predictions for the initial five years from the start dates are examined here. Areas where ratios of RMS errors to observed RMS amplitudes are smaller than unity are hatched. Before calculating the observed RMS amplitudes, observed anomalies are detrended to take into account internal variations only.

Generally, distribution patterns of RMS errors for each variable are similar among the models. This is presumably because regions with larger RMS errors also have larger RMS amplitudes of internal variations in the models and the observations (not shown). RMS errors of VAT300 are smaller in the tropical and subtropical Atlantic, the subtropical North Pacific, the Indian Ocean, and the Southern Ocean than in other regions. The RMS errors of SAT are similarly distributed to those of VAT300 over the oceans. Over continents, especially the Eurasian and North American continents, the RMS errors of SAT are remarkably large as seen in the assimilation runs (Fig. 7). The RMS errors of SLP are relatively small in the low- and mid-latitudes over the oceans except for the regions around the Aleutian low center. In comparison with the RMS errors in the assimilation runs (Figs. 
(a)

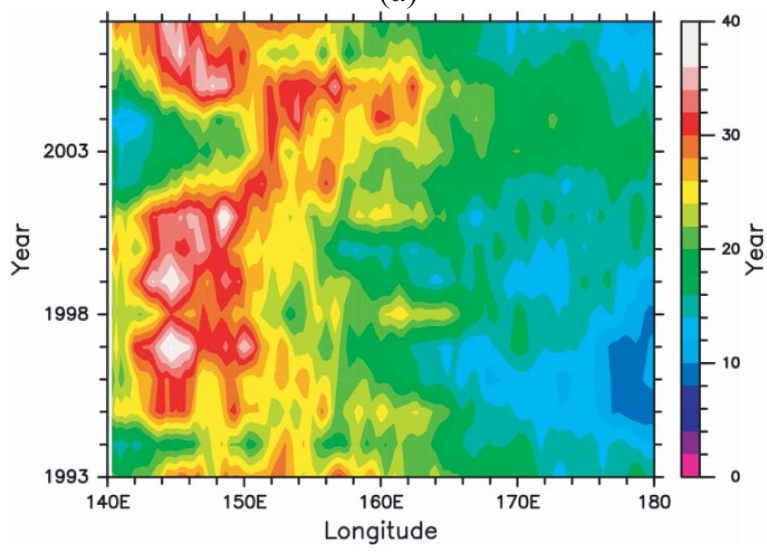

(b)

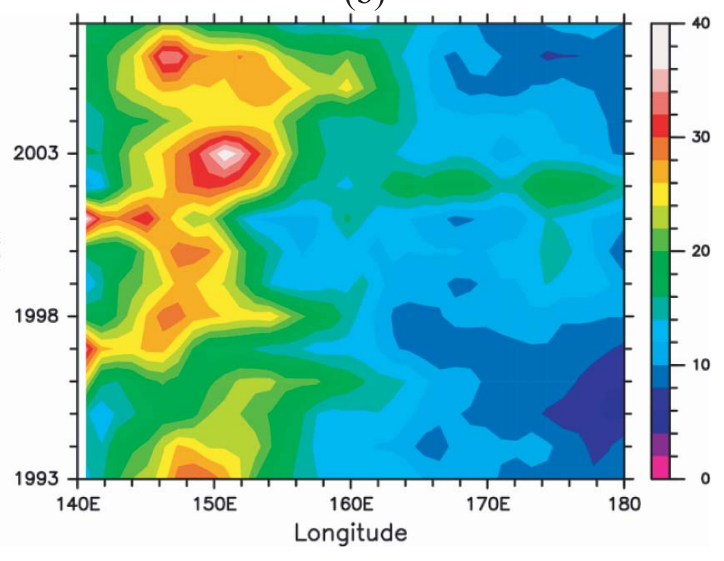

Fig. 12. Time-longitude plots of square root of EKE (unit; $\mathrm{cms}^{-1}$ ) in (a) the observations and (b) the MIROC4h assimilation run averaged between $32^{\circ} \mathrm{N}$ and $38^{\circ} \mathrm{N}$.

(a) VAT300, MIROC4h

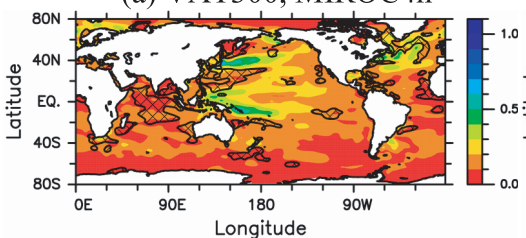

(d) SAT, MIROC4h

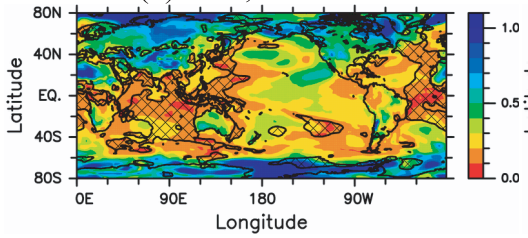

(g) SLP, MIROC4h

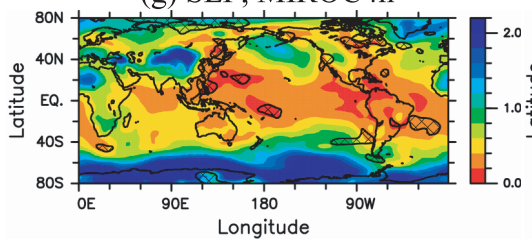

(b) VAT300, MIROC5

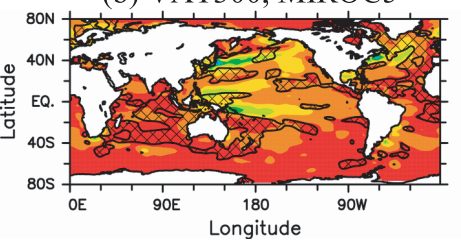

(e) SAT, MIROC5

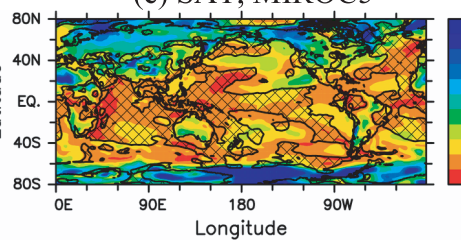

(h) SLP, MIROC5 (c) VAT300, MIROC3m

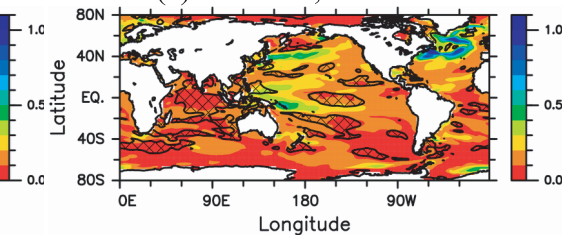

(f) SAT, MIROC $3 \mathrm{~m}$

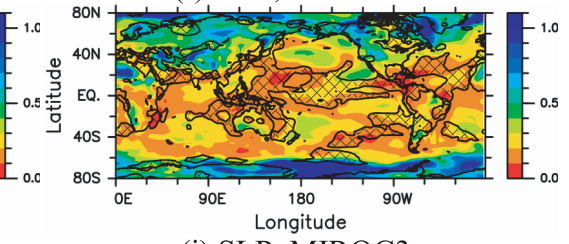

(i) SLP, MIROC $3 \mathrm{~m}$
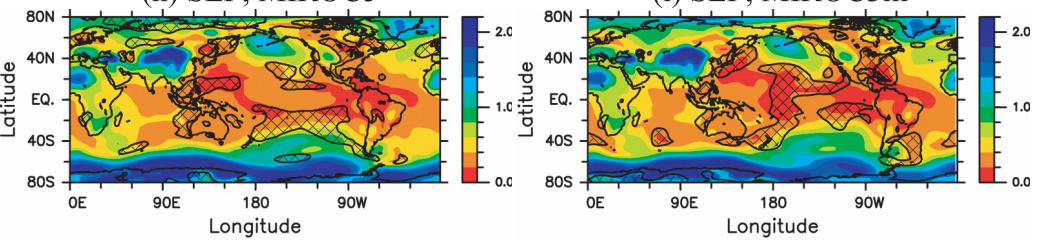

Fig. 13. RMS errors (shades) of VAT300 (unit; K), SAT (K), and SLP (hPa) between the observations and the initialized hindcast runs. The errors are calculated in the initial five years from the start dates of predictions. Areas where ratios of RMS errors to observed RMS amplitudes are smaller than unity are hatched. Before calculating the observed RMS amplitudes, anomalies are detrended to take into account internal variations only.

5 and 7), those of VAT300, SAT in the hindcast experiments are much larger over the oceans, especially in regions where amplitudes of decadal internal variations are remarkable (namely, the KO zone, the western equatorial Pacific, and the subarctic North Atlantic). On the other hand, RMS errors of SLP in the hindcast runs are twice as large as those in the assimilation runs.

As indicated by hatched regions in Fig. 13, RMS errors of VAT300 and SAT are significantly small in the subtropical North Pacific and the Indian Ocean in all the models, and these variables seem 
to be predictable on a decadal scale. In addition, SAT predicted by MIROC5 and MIROC3m are skillful in the equatorial Pacific and Atlantic, the North Atlantic, and to the east of Australia. Distributions of skillful regions for SLP prediction are not common among the models. RMS errors of SST, SAT, and VAT300 of the initialized hindcast runs are smaller compared with whose of the uninitialized 20C3M runs. In our companion papers by Chikamoto et al. (2011b) and Mochizuki et al. (2011), predictability of specific variables such as global mean SAT, PDO and AMO indices in the initialized runs are discussed. They show the initialization of the MIROC climate models successfully reduces RMS errors of the global mean SAT, PDO and AMO predictions more than those of the uninitialized runs as well as a simple damped persistence statistical model. Refer to Chikamoto et al. (2011b) and Mochizuki et al. (2011) which analyze the model ensemble data of the MIROC climate models, for further details.

The magnitudes of the RMS errors of the MIR$\mathrm{OC} 4 \mathrm{~h}$ hindcast experiments are somewhat large in comparison with the others. It is considered that the poor skill of MIROC4h may be due to the lowest number of ensemble members, that is three, among the models. To reduce uncertainty in the prediction skills by MIROC4h, we are planning to increase the number of ensemble members.

\section{Summary and discussion}

This paper summarizes procedure for ocean data assimilation that initializes the MIROC climate models for decadal hindcast and forecast experiments for the IPCC AR5 and CMIP5. The historical ocean temperature and salinity analysis of Ishii and Kimoto (2009) are assimilated into the ocean models of the climate models, using the IAU method. So-called 'anomaly assimilation' is adopted in order to prevent model climate drift during predictions. In initializing MIROC4h which has an eddy-permitting ocean model, a spatial smoother is applied in computing analysis increments so that oceanic mesoscale eddies cannot be damped by constraints of the observations given on the coarse grid. Owing to this, mesoscale eddies in the model can thus be generated and decay physically in response to variations of assimilated hydrographic structures and resultant background currents on large horizontal scales.

In the assimilation runs, 5-yr-mean anomalies of SST and VAT300 are highly correlated with the observations, and the RMS errors are mostly insignificant except for some specific regions such as the western boundary current regions. As for atmospheric variables, which are not constrained by any observations directly, SLP and SAT variations in the assimilation runs are synchronized with the observations over the oceans, except for SLP in the mid- to high-latitudes. Over the land, however, both SLP and SAT in the assimilation runs tend to be weakly or negatively correlated with the observations and have significant RMS errors compared to the observed RMS amplitudes.

We have also examined the decadal climate variabilities in comparison with the observations. SAT and SLP variations associated with the PDO and the AMO in the models are consistent with the observations, while the precipitation patterns are not well represented in MIROC $3 \mathrm{~m}$. It is speculated that the improved atmospheric responses are due to the higher resolution of MIROC4h and the newly implemented cloud parameterizations of MIROC5, respectively.

In the assimilation run and the $20 \mathrm{C} 3 \mathrm{M}$ runs of MIROC4h, there are prominent signals of oceanic mesoscale eddies in the regions with strong currents and oceanic fronts such as the Kuroshio-Oyashio confluence zone and the Gulf Stream Extension. Distributions of eddy activity defined by RMS amplitudes of high-pass filtered SSH anomalies with periods shorter than 300 days in the models are consistent with the observations. The eddy activity and characteristics of oceanic eddies in the assimilation run are similar to those in the 20C3M runs, owing to the data assimilation scheme specified for the eddy-permitting model. In the KuroshioOyashio confluence zone, eddy activity is modulated on a decadal scale and consistent with the observations. It is noticeable that if variations in large-scale hydrographic structures are assimilated modulations of eddy activity can be represented without any observational constraints on eddies.

The present procedure for climate model initialization leads to no model climate drifts during predictions and ensures skills in decadal climate predictions. RMS errors of VAT 300 and SAT between the hindcasts and the observations in the initial five years from the start dates of predictions are significantly small in the subtropical North Pacific and the Indian Ocean in all versions of MIROC, compared to the RMS errors in other regions. In the equatorial Pacific and Atlantic, the North Atlantic, and to the east of Australia, SAT 
predicted by MIROC5 and MIROC3m are also skillful. Although we have shown only the RMS errors in the initial 5 years, the model climates do not have remarkable drifts in the last half of the 10 -year-long predictions. Specific issues with regard to decadal predictions with MIROC, for example, skills in predicting the PDO and the AMO, and the stepwise climate shift in the late 1990s in the Pacific, are discussed in our companion papers (e.g., Chikamoto et al. 2011ab; Mochizuki et al. 2010, 2011; Yasunaka et al. 2011).

In the present study, only rather a simplified scheme, the IAU scheme, is used for initializing the climate models for decadal predictions and socalled 'anomaly assimilation' is adopted. Methodologies of climate model initialization need to be further discussed. For example, how effective is a high-end analysis scheme such as the ensemble Kalman filter for assimilating not only ocean hydrographic data but also atmospheric variables? Which of the anomaly assimilation and the full field assimilation does ensure more skillful decadal predictions? These remaining issues will be addressed in future.

The decadal hindcast and forecast experiments using MIROC have also been conducted to provide a basis for quantitative assessment of changes in regional climate, extreme weather events, ecosystem variations, and so on. It is expected that decadal climate predictions using MIROC will contribute to the IPCC AR5 and political decision-makings for the coming decades.

\section{Acknowledgements}

This study is supported by the Japanese Ministry of Education, Culture, Sports, Science and Technology, through the Innovative Program of Climate Change Projection for the 21th Century. The numerical experiments were carried out on the Earth Simulator, and the figures in the present manuscript were prepared with the GFD-Dennou library. The authors are much indebted to Mr. Hiroaki Kanai. We thank the two anonymous reviewers for their valuable comments and English grammatical corrections.

\section{References}

Bloom, S. C., L. Takacs, A. M. Da Silva, and D. Ledvina, 1996: Data assimilation using Incremental analysis updates. Mon. Wea. Rev., 124, 1256-1271.

Cayan, D. R., A. A. Kammerdiener, M. D. Dettinger,
J. M. Caprio, and D. H. Peterson, 2001: Changes in the onset of spring in the western United States. Bull. Amer. Meteor. Soc., 82, 399-415.

Chikamoto, Y., M. Kimoto, M. Ishii, M. Watanabe, T. Nozawa, T. Mochizuki, H. Tatebe, T. T. Sakamoto, Y. Komuro, H. Shiogama, M. Mori, S. Yasunaka, Y. Imada, H. Koyama, M. Nozu, and F.-F. Jin, 2011a: Predictability of a stepwise shift in the Pacific climate during the late 1990s in hindcast experiments using MIROC. J. Meteor. Soc. Japan, 90A, 1-21.

Chikamoto, Y., M. Kimoto, M. Ishii, M. Watanabe, T. Nozawa, T. Mochizuki, H. Tatebe, T. T. Sakamoto, Y. Komuro, H. Shiogama, M. Mori, S. Yasunaka, Y. Imada, H. Koyama, M. Nozu, and F.-F. Jin, 2011b: Overview of decadal climate predictability by multi-model ensemble in MIROC, in preparation.

Chikira, M., and M. Sugiyama, 2010: A cumulus parameterization with state-dependent entrainment rate. Part I: Description and sensitivity to temperature and humidity profiles. J. Atmos. Sci., 67, 21712193.

Collins, M., A. Botzet, A. F. Carril, H. Drange, A. Jouzeau, M. Latif, S. Masina, O. H. Otteraa, H. Pohlmann, A. Sorteberg, R. Sutton, and L. Terray, 2006: Interannual to decadal climate predictability in the North Atlantic: A multimodel-ensemble study. J. Climate, 19, 1195-1203.

Düeing, W., P. Hisard, E. Katz, J. Meincke, L. Miller, K. V. Moroshkin, G. Philander, A. A. Ribnikov, K. Voigt, and R. Weisberg, 1975: Meanders and long waves in the equatorial Atlantic. Nature, 257, 280-284.

Enfield, D. B., A. M. Mestas-Nuñez, and P. J. Trimble, 2001: The Atlantic Multidecadal Oscillation and its relationship to rainfall and river flows in the continental U.S. Geophys. Res. Lett., 28, 20772080.

Griffies, S. M., and K. Bryan, 1998: Predictability of the North Atlantic multidecadal climate variability. Science, 275, 181-184.

Hashioka, T., T. T. Sakamoto, and Y. Yamanaka, 2009: Potential impact of global warming on North Pacific spring blooms projected by an eddypermitting 3-D ocean ecosystem model. Geophys. Res. Lett., 36, doi:10.1029/2009GL038912.

Huang, B., J. Kinter, and P. Schopf, 2002: Ocean data assimilation using intermittent analyses and continuous model error correction. Adv. Atmos. Sci., 19, 965-992.

Ishii, M., M. Kimoto, K. Sakamoto, and S. I. Iwasaki, 2006: Steric sea level changes estimated from historical subsurface temperature and salinity analyses. J. Oceanogr., 61, 155-170.

Ishii, M., and M. Kimoto, 2009: Reevaluation of histori- 
cal ocean heat content variations with time-varying XBT and MBT depth bias corrections. J. Oceanogr., 65, 287-299.

Ishikawa, I., and H. Ishizaki, 2009: Importance of eddy representation for modeling the intermediate salinity minimum in the North Pacific: comparison between eddy-resolving and eddy-permitting models. J. Oceanogr., 65, 407-426.

K-1 model developers, 2004: K-1 coupled GCM (MIROC) description, K-1 Tech. Rep., 1, edited by H. Hasumi and S. Emori, 34 pp., Center for Climate System Research, the Univ. of Tokyo, Tokyo.

Kalnay, E., M. Kanamitsu, R. Kistler, W. Collins, D. Deaven, L. Gandin, M. Iredell, S. Saha, G. White, J. Woollen, Y. Zhu, M. Chelliah, W. Ebisuzaki, W. Higgins, J. Janowiak, K. C. Mo, C. Ropelewski, J. Wang, A. Leetmaa, R. Reynolds, R. Jenne, and D. Joseph, 1996: The NCEP/ NCAR 40-year reanalysis project. Bull. Am. Meteor. Soc., 77, 437-471.

Keenlyside, N. S., M. Latif, J. Jungclaus, L. Kornblueh, and E. Roeckner, 2008: Advancing decadal-scale climate prediction in the North Atlantic sector. Nature, 453, 84-88.

Kerr, R. A., 2000: A North Atlantic climate pacemaker for the centuries. Science, 288, 1984-1985.

Komori, N., W. Ohfuchi, B. Taguchi, H. Sasaki, and P. Klein, 2008: Deep ocean inertia-gravity waves simulated in a high-resolution global coupled atmosphere-ocean GCM. Geophys. Res. Lett., 35, doi:10.1029/2007GL032807.

Komuro, Y., T. Suzuki, T. T. Sakamoto, H. Hasumi, M. Ishii, M. Watanabe, T. Nozawa, T. Yokohata, T. Nishimura, K. Ogochi, S. Emori, and M. Kimoto, 2011: Sea-ice in twentieth-century simulations by new MIROC coupled models: a comparison between models with high resolution and with ice thickness distribution. J. Meteor. Soc. Japan, 90A, 213-232.

Legeckis, R., 1977: Long waves in the eastern equatorial Pacific Ocean: A view from a geostationary satellite. Science, 197, 1177-1181.

Levitus, S., and T. Boyer, 1994: World Ocean Atlas 1994, vol. 4 Temperature, NOAA Atlas NESDIS4, Gov. Print. Off., Washington, D.C., 150 pp.

Mantua, N. J., S. R. Hare, Y. Zhang, J. M. Wallace, and R. C. Francis, 1997: A Pacific interdecadal climate oscillation with impacts on salmon production. Bull. Amer. Meteor. Soc., 78, 10691079.

Mantua, N. J., and S. R. Hare, 2002: The Pacific Decadal Oscillation. J. Oceanogr., 58, 35-44.

Mochizuki, T., M. Ishii, M. Kimoto, Y. Chikamoto, M. Watanabe, T. Nozawa, T. T. Sakamoto, H. Shiogama, T. Awaji, N. Sugiura, T. Toyoda,
S. Yasunaka, H. Tatebe, and M. Mori, 2010: Pacific decadal oscillation hindcasts relevance to near-term climate prediction. Proc. Natl. Acad. Sci. USA, 107, doi:10.1073/pnas.0906531107.

Mochizuki, T., M. Kimoto, M. Ishii, Y. Chikamoto, H. Tatebe, Y. Komuro, T. T. Sakamoto, and M. Mori, 2011: Decadal prediction using a recent series of MIROC global climate models. J. Meteor. Soc. Japan, 90A, 373-383.

Nozawa, T., T. Nagashima, H. Shiogama, and S. A. Crooks, 2005: Detecting natural influence on surface air temperature change in the early twentieth century. Geophys. Res. Lett., 32, doi:10.1029/ 2005GL023540.

Pohlmann, H., M. Botzet, M. Latif, A. Roesch, M. Wild, and P. Tschuck, 2004: Estimating the decadal predictability of a coupled AOGCM. J. Climate, 17, 4463-4472.

Pohlmann, H., J. H. Jungclaus, A. Köhl, D. Stammer, and J. Marotzke, 2009: Initializing decadal climate predictions with the GECCO oceanic synthesis: Effect on the North Atlantic. J. Climate, 22, 3926-3938.

Qiu, B., and S. Chen, 2005: Variability of the Kuroshio Extension jet, recirculation gyre, and mesoscale eddies on decadal time scales. J. Phys. Oceanogr., 35, 2090-2103.

Sakamoto, T., and co-authors, 2011: MIROC4-a new high-resolution CCSR/NIES/JAMSTEC atmosphere-ocean coupled model. J. Meteor. Soc. Japan.

Schlesineger, M. E., and N. Ramankutty, 1993: An oscillation in the global climate system of period 65-70 years. Nature, 367, 723-726.

Sekiguchi, M., and T. Nakajima, 2008: A $k$-distribution based radiation code and its computational optimization for an atmospheric general circulation model. J. Quant. Spectrosc. Radiat. Transfer, 109, 2779-2793.

Smith, D. M., S. Cusack, A. W. Colman, C. K. Folland, G. R. Harris, J. M. Murphy, 2007: Improved surface temperature prediction for the coming decade from a global climate model. Science, 317, 796799.

Sugiura, N., T. Awaji, S. Masuda, T. Toyoda, H. Igarashi, M. Ishii, and M. Kimoto, 2009: Potential for decadal predictability in the North Pacific region. Geophys. Res. Lett., 36, doi:10.1029/ 2009GRL039787.

Sumata, H., T. Hashioka, T. Suzuki, N. Yoshie, T. Okunishi, M. N. Aita, T. T. Sakamoto, A. Ishida, N. Okada, and Y. Ymanaka, 2010: Effect of eddy transport on the nutrient supply into the euphotic zone simulated in an eddypermitting ocean ecosystem model. J. Mar. Syst., 83, 67-68 
Sutton, R. T., and D. L. R. Hudson, 2005: Atlantic Ocean forcing of North American and European summer climate. Science, 309, 115-118.

Suzuki, T., H. Hasumi, T. T. Sakamoto, T. Nishimura, A. Abe-Ouchi, T. Segawa, N. Okada, A. Oka, and S. Emori, 2005: Projection of future sea level and its variability in a high-resolution climate model: Ocean processes and Greenland and Antarctic ice-melt contributions. Geophys. Res. Lett., 32, doi:10.1029/2005GL023677.

Takata, K., S. Emori, and T. Watanabe, 2003: Development of the minimal advanced treatments of surface interaction and runoff. Global Planet. Change, 38, 209-222.

Tatebe, H., and H. Hasumi, 2010: Formation mechanism of the Pacific equatorial thermocline revealed by a general circulation model with a high accuracy tracer advection scheme. Ocean Modell., 35, 245252.

Watanabe, M., S. Emori, M. Satoh, and H. Miura, 2009: A PDF-based hybrid prognostic cloud scheme for general circulation models. Clim. Dyn., 33, doi:10.1007/s00382-008-0489-0.

Watanabe, M., T. Suzuki, R. O'ishi, Y. Komuro, S. Watanabe, S. Emori, T. Takemura, M. Chikira, T. Ogura, M. Sekiguchi, K. Takata, D. Yamazaki,
T. Yokohata, T. Nozawa, H. Hasumi, H. Tatebe, and M. Kimoto, 2010: Improved climate simulation by MIROC5: Mean states, variability, and climate sensitivity. J. Climate, 23, 6312-6335.

Xie, P., and P. A. Arkin, 1997: Global precipitation: a 17-year monthly analysis based on gauge observations, satellite estimates, and numerical model outputs. Bull. Amer. Meteor. Soc., 78, 2539-2558.

Yamazaki, D., T. Oki, and S. Kanae, 2009: Deriving a global river network map and its sub-grid topographic characteristics from a fine-resolution flow direction map. Hydrol. Earth Syst. Sci., 13, 22412251.

Yasuda, I., K. Okuda, and Y. Shimizu, 1996: Distribution and modification of North Pacific Intermediate Water in the Kuroshio-Oyashio interfrontal zone. J. Phys. Oceanogr., 26, 448-465.

Yasuda, I., 1997: The origin of North Pacific Intermediate Water. J. Geophys. Res., 102, 893-909.

Yasunaka, S., M. Ishii, M. Kimoto, T. Mochizuki, and H. Shiogama, 2011: Influence of XBT temperature bias on decadal climate prediction with a coupled climate model. J. Climate, 24, 5303-5308.

Zhang, R., and T. L. Delworth, 2005: Simulated response to a substantial weakening of the Atlantic thermohaline circulation. J. Climate, 18, 1853-1860. 